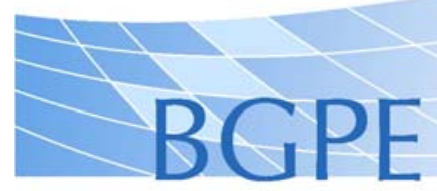

Bavarian Graduate Program in Economics

BGPE Discussion Paper

No. 184

\title{
Nonhomothetic Preferences and Rent Sharing in an Open Economy
}

\author{
Hartmut Egger \\ Simone Habermeyer
}

February 2019

ISSN 1863-5733

Editor: Prof. Regina T. Riphahn, Ph.D.

Friedrich-Alexander-Universität Erlangen-Nürnberg

(C) Hartmut Egger, Simone Habermeyer 


\title{
Nonhomothetic Preferences and Rent Sharing in an Open Economy*
}

\author{
Hartmut Egger $\$$ \\ University of Bayreuth \\ CESifo, GEP, and IfW
}

\author{
Simone Habermeyer \\ University of Bayreuth
}

February 13, 2019

\begin{abstract}
We develop a framework for studying how differences in the level and/or dispersion of per-capita income affect trade structure and welfare in a two-country model. Thereby, we embed nonhomothetic preferences into a home-market model with two sectors of production and one input factor. We associate the outside good with a necessity and the differentiated good with a luxury, and we assume that heterogeneity of income arises due to heterogeneity of households in their effective labor supply. We then show that in line with the home-market effect countries have a trade surplus in the good for which they have relatively higher domestic demand, making the country with a higher level and/or dispersion of per-capita income a net-exporter of luxuries. The structure of trade is irrelevant for welfare in the open economy if both sectors pay the same wage. If, however, the sector producing luxuries pays a wage premium due to rent sharing, there are feedback effects of trade on the level and dispersion of per-capita income, which can lead to losses from trade in the country net-exporting necessities. In an extension of our model, we show that our results remain intact when we allow for positive assortative matching of workers featuring high effective labor supply with jobs offering high wages in the sector of luxuries. In a second extension, we show that the assumption of nonhomothetic preferences seems less important when supply-side differences are the main motive for inter-industry trade.
\end{abstract}

Keywords: Nonhomothetic preferences; Rent sharing; Trade structure; Welfare effects of trade

JEL Classification: F12, F16, D11

\footnotetext{
${ }^{*}$ We are grateful to Timo Boppart, Carsten Eckel, Sergey Kichko, John Morrow, Peter Neary, Marc Muendler, Federico Trionfetti as well as participants of the TRISTAN Workshop at the University of Bayreuth, the Göttingen Workshop on International Economics, the Research Workshop of the Bavarian Graduate Program in Economics, the European Trade Study Group, and Research Seminars at Aix Marseille University, the Universities of Bayreuth, Hagen, Munich, and Nuremberg for helpful comments and suggestions.

${ }^{\S}$ Corresponding author: University of Bayreuth, Department of Economics, Universitaetsstr. 30, 95447 Bayreuth, Germany; hartmut.egger@uni-bayreuth.de.
} 
"Trade operates with [... a] fundamental bias in favor of richer and progressive regions against the other regions [... so] that even the handicrafts and industries existing earlier in the other regions are thwarted."

- Myrdal (1957, p. 28)

\section{Introduction}

Comparative advantage has been widely acknowledged as the engine of international trade and an important source of welfare gain since David Ricardo's book "On the Principles of Political Economy and Taxation" more than two centuries ago. It took almost one and a half centuries before the dominance of this supply-side view has been broken by Linder's (1961) hypothesis that demand-side factors are also important for explaining international trade patterns. Providing a first, informal account of a new trade theory that emphasizes mutual exchange of goods within industries between similar countries, the first fully-fledged model of intra-industry trade is due to Krugman $(1979,1980)$. Krugman's new trade theory highlights similarity in market size as a key determinant of international trade, whereas Markusen (1986) and Flam and Helpman (1987) show that the level and dispersion of income constitute further demandside factors when deviating from the assumption of homothetic preferences. This makes two variables, whose changes to international trade have been the target of economic research for a long time, determinants of the existence of trade. The last two decades have seen a revived interest in models featuring nonhomothetic preferences, as they promise a better description of real world trade flows (cf. Fajgelbaum et al., 2011; Markusen, 2013). We use them here to study under which conditions Myrdal's widely shared concern that trade widens the gap between rich and poor countries is justified and show that it is not only the difference in the initial level but also in the dispersion of per-capita income that matters for the welfare effects of trade.

For this purpose, we introduce a class of nonhomothetic preferences that are simple enough to warrant analytical tractability of a model featuring trade between two countries, which differ in the level and/or dispersion of per-capita income, and allow to dissect the welfare effects of this asymmetry into an exogenous component, determining the trade pattern in the open economy, and an endogenous component, capturing the feedback effects of trade. We consider a two-sector economy that adopts important features of the home-market model proposed by Helpman and Krugman (1985). There is one sector with monopolistic competition producing differentiated varieties and another sector producing a homogeneous good under perfect competition, with both sectors using labor as the only input of production. Due to the assumption of nonhomothetic preferences, we can give the output produced by the two sectors an intuitive interpretation from consumer theory. The differentiated goods are luxuries and the homogeneous good is a necessity, as suggested by Francois and Kaplan (1996). Since the expenditure share for luxuries increases in income, the assumption of nonhomothetic preferences makes the level and dispersion of percapita income important determinants of the size of the home market for luxuries and hence also crucial factors of the trade pattern in the open economy. To distinguish ex ante differences in the level and/or dispersion of per-capita income from ex post differences materializing from trade liberalization, we impose two additional assumptions. On the one hand, we assume that households differ in their effective labor 
supply (as in Fajgelbaum et al., 2011) and, on the other hand, we consider firm-level rent sharing through individual bargaining (as in Helpman and Itskhoki, 2010) to generate sector-specific wages and allow for feedback effects of trade on nominal wage income.

To model nonhomothetic utility, we rely on "price-independent generalized-linear" (PIGL) preferences proposed by Muellbauer $(1975,1976)$. These preferences are more general than the Gorman class, but still admit a representative consumer, who is characterized by an expenditure level for which the value (expenditure) shares of consumption equal the value shares of the aggregate economy. ${ }^{1}$ The existence of a representative consumer makes these preferences particularly suited for aggregating consumer demand over households with heterogeneous income. However, PIGL preferences have the disadvantage that an explicit solution for the direct utility function usually does not exist. This makes identifying a proper consumer price index under imperfect competition a difficult task. To overcome this problem, we use a subclass of PIGL preferences, for which a closed form representation of the direct utility function can be determined (see Boppart, 2014). This subclass is still general enough to cover two prominent preference specifications as limiting cases. The first one are homothetic Cobb-Douglas preferences and the second one are nonhomothetic quasilinear preferences. In both cases, preferences have Gorman form with linear Engel curves so that, by assumption, changes in the dispersion of income do not affect market demand. Except for these limiting cases Engel curves are, however, not linear. They are convex for luxuries and concave for necessities. With non-linear Engel curves, the representative consumer used for aggregation does not have a normative interpretation. To discuss welfare implications of trade, we therefore must take a stance on distributional justice and we do so by choosing a utilitarian perspective that gives each household the same weight in the social welfare function. ${ }^{2}$

Due to the non-linearity of Engel curves, demand for luxuries is larger in the country that features a higher level and/or higher dispersion of per-capita income, which, following the reasoning from the literature on home-market effects, is the country that has a trade surplus in luxuries in the open economy. Larger differences of countries in their expenditure structure lead to a stronger specialization in production, raising inter- and reducing intra-industry trade. Therefore, the model considered here is consistent with Linder's (1961) hypothesis that more equal per-capita income levels of two economies provide larger

\footnotetext{
${ }^{1}$ As put forward by Muellbauer (1975), PIGL preferences are the most general class of preferences that avoid an aggregation problem with heterogeneous households by admitting a well-defined representative consumer. If the thus defined expenditure level corresponds to the mean of expenditures, PIGL preferences have Gorman form.

${ }^{2}$ One may prefer a prioritarian view on distributional justice that gives higher weight to poorer households (cf. Parfit, 1997). However, since our welfare function features social inequality aversion even when weighting poor and rich households equally, a prioritarian view would not have a large impact on our qualitative results. Furthermore, one may be more interested in changes in real GDP per-capita than changes in welfare. However, determining real GDP per-capita requires the construction of an exact consumer price index. Whereas Feenstra and Reinsdorf (2000) and Hamilton (2001) have made significant progress in determining such an exact price index for a class of nonhomothetic preferences introduced by Deaton and Muellbauer (1980), which deliver an almost ideal demand system (AIDS), their insights are of limited help for our analysis. On the one hand, except for the limiting case of Cobb-Douglas, the preferences considered here do not belong to this class (see Pollak and Wales, 1992, for a discussion). On the other hand, Almås et al. (2018) point out that computing a single consumer price index has the inherent problem of disregarding the fact that households with different income levels differ in their expenditure shares if preferences are nonhomothetic. Hence, choosing a single consumer price index fails the purpose of measuring the cost-of-living of heterogeneous households. To avoid the problems associated with constructing a proper consumer price index, we therefore focus on the effects on welfare instead of real GDP in our analysis.
} 
scope for (intra-industry) trade in those goods, for which local demand is an important determinant of production. ${ }^{3}$ As put forward by Davis (1998), the home-market effect is more pronounced at lower trade costs, making intra-industry trade less important if the two economies become more integrated. If both sectors pay the same wage, there are gains from trade in our model, which are independent of the trade structure in the open economy and thus the same for the two economies. This changes when employment in the sector of luxuries promises a wage premium, so that the allocation of workers influences the level and dispersion of per-capita income. In this case, the trade pattern becomes a determinant of welfare with two important consequences for our analysis.

First, there are nominal income losses for workers losing their jobs in the production of luxuries, which captures the widespread concern that not all workers equally benefit from globalization. Whereas this insight is not new and has received a lot of media attention through recent publications by Autor et al. (2013) and Dauth et al. (2014), our analysis points to the role of demand-side factors and shows that losers are more likely to be found in countries with a lower initial per-capita income level. However, things can be even worse for the poorer economy. Losing market share in the sector of luxuries can lead to an increase in the consumer price index and hurt all households. Hence the specialization of production, while usually understood as an important channel for generating gains from trade, can be a source of welfare loss. Losses from trade can exist in our model only for the country that loses market share in the sector featuring increasing external economies to scale. However, in contrast to insights from Graham (1923), Markusen and Melvin (1981), and Ethier (1982), it is not the existence of external economies to scale per se that gives scope for welfare loss. Rather losses from trade are the result of a price distortion in the labor market, which makes our results akin to findings by Brecher (1974) and Davis (1998) and builds on the fundamental insight from the theory of second best that welfare losses from trade are possible if the market equilibrium in the closed economy has not been socially optimal (cf. Markusen, 1981; Newbery and Stiglitz, 1984). Our analysis shows that welfare losses can result from differences in demand-side factors and exist although the price distortions in the labor market are the same in the two economies.

Second, with non-linear Engel curves the concentration of disposable income becomes a further determinant of the home market for luxuries. A lower dispersion of disposable income can make a country net-importer of luxuries and therefore worse off with trade than under autarky. This insight challenges policy measures put forward by the literature to distribute the gains from trade more equally. On the one hand, it cannot be ruled out that all households lose from trade, leaving no scope for a redistributive policy intervention. On the other hand, a policy intervention that targets ex ante sources or ex post realizations of an unjust distribution, while maintaining gains from trade in the aggregate, may not be feasible. Lowering the dispersion of per-capita income decreases the home market for luxuries with potentially detrimental welfare consequences. Therefore, the analysis in this paper raises doubts that so far discussed policy measures remain promising instruments to increase support for trade liberalization (cf. Davidson

\footnotetext{
${ }^{3}$ Empirical evidence in favor of the Linder (1961) hypothesis has been reported, for instance, by Thursby and Thursby (1987), Bergstrand (1989, 1990), and Hallak (2010). Francois and Kaplan (1996), Dalgin et al. (2008), Bernasconi (2013), and Vollmer and Martínez-Zarzoso (2016) show that bilateral trade is not only affected by differences in the level of per-capita income but also by differences of the two trading partners in their distributions of income.
} 
and Matusz, 2006; Egger and Fischer, 2018), when accounting for demand-side determinants of trade in a setting with nonhomothetic preferences.

We complement our analysis on the link between trade patterns and welfare by two extensions of our model. In the first extension, we give up the simplifying assumption that workers are assigned to the production of luxuries by a lottery that does not discriminate between different levels of effective labor supply. This is, because in the benchmark model firms producing luxuries have to pay the same job installment costs for each unit of labor input and are therefore indifferent between employing workers with low or high effective labor supply. Assuming instead that firms have to pay the same job installment costs per worker, gives them an incentive for selecting applicants with higher effective labor supply to reduce their employment costs. If screening the pool of applicants is not costless and gives an imprecise signal about the effective labor supply (as in Helpman et al., 2010), the thus modified framework features endogenous fixed and variable production costs in the sector of luxuries and thus an additional margin for adjustments to trade. Despite these complications the results from our analysis are largely unaffected. In a second extension, we analyze whether the choice of preferences is also important for understanding the consequences of supply-side differences for trade structure and welfare, pointing to a determinant of the international exchange of goods that has been put forward by traditional models of trade theory. We consider differences in the price distortion at the labor market as the supply-side asymmetry of the two economies and, to keep things simple, assume that rent sharing only exists in the foreign economy. This gives home a comparative advantage in the production of luxuries, making it a net-exporter of these goods in the open economy. As a consequence, home gains from trade, whereas the welfare effects in foreign are less clear. We show that irrespective of the specific nature of preferences, foreign loses from a small reduction of initially high trade costs if the price distortion in the labor market is high, while it benefits from the decline in trade costs if the price distortion is small. This result is in line with the more general observation that welfare losses from forfeiting market share in the sector exhibiting increasing external economies to scale are more likely if trading partners are more dissimilar (cf. Francois and Nelson, 2002).

Emphasizing the role of demand-side factors for explaining trade patterns in a setting with nonhomothetic preferences, we build on work by Markusen (1986, 2013) and Bergstrand (1990) who employ Stone-Geary preferences to explain how differences in per-capita income affect the trade structure in open economies. ${ }^{4}$ Simonovska (2015) uses Stone-Geary preferences to explain the positive relationship between (relative) prices of tradable goods and per-capita income. Relying on preferences that produce linear Engel curves, market demand in these settings is independent of the distribution of income and an aggregation problem over heterogeneous households therefore does not exist. The aggregation problem is also avoided by a number of studies using non-Gorman form preferences with symmetric households. An early prominent example in this respect is Stockey (1991), who considers nonhomothetic preferences in a setting with vertically differentiated products to shed light on the trade structure between rich and

\footnotetext{
${ }^{4}$ Bergstrand (1989) shows how the gravity equation has to be adjusted in order to account for differences in per-capita income along with differences in factor endowments as key determinants of bilateral trade. Hunter (1991) provides early empirical evidence that accounting for per-capita income differences may explain missing trade in empirical work based on Heckscher-Ohlin models.
} 
poor countries and to explain empirical evidence that new, high quality products are first consumed in rich countries and are only at later stages also consumed in poor countries. Fieler (2011) introduces preferences that do not have Gorman form to explain the role of per-capita income for trade structure in a multi-country Ricardian model along the lines of Eaton and Kortum (2002), and she uses this model to show that a technology shock in China has different effects on countries with differing per-capita income levels. Caron et al. (2014) employ nonhomothetic preferences to improve the predictions of the Heckscher-Ohlin Vanek model regarding the factor content of trade and show that their correction is quantitatively important. Matsuyama (2015) introduces nonhomothetic preferences into a home-market model to study the effects of per-capita income differences on trade structure and to analyze how the benefits of technological progress are distributed between the rich and the poor country. Matsuyama (2018) uses the same class of preferences to show how trade liberalization and economic growth affect the patterns of structural change, innovation, and trade in the presence of Engel's Law. ${ }^{5}$ Whereas these models do not provide new insights for the aggregation of consumer demand over heterogeneous households, the preferences are useful for aggregating consumer demand over heterogeneous goods, and hence for solving a problem that is relevant for quantitative studies.

A final group of studies avoids problems from aggregating consumer demand over households with heterogeneous income levels by making the consumption decision a binary choice. For instance, Matsuyama (2000) imposes nonhomothetic '0-1' preferences into a Ricardian model of North-South trade with a continuum of goods and shows that acknowledging the nonhomotheticity of preferences changes the insights from an otherwise identical Dornbusch et al. (1977) model regarding the role of technological advancement, population growth, and income redistribution in the South on the terms-of-trade and welfare in the two economies. ${ }^{6}$ Fajgelbaum et al. (2011) build on the preference structure proposed by Flam and Helpman (1987) and assume that households purchase one unit of a vertically differentiated good and allocate the rest of their expenditures on the consumption of a homogeneous outside good. Assuming that quality of the differentiated good and quantity of the homogeneous good are complements makes their preferences nonhomothetic, because the impact of income on indirect utility depends on the chosen quality of the differentiated good. To allow for monopolistic competition between firms producing horizontally differentiated varieties of the same quality level, Fajgelbaum et al. (2011) augment their discrete choice mechanism with a stochastic utility term (similar to McFadden, 1978), and they use this framework

\footnotetext{
${ }^{5}$ Both Fieler (2011) and Caron et al. (2014) build on a generalized CES preference structure, in which the demand elasticities of income and prices are constant and proportional (as suggested by Pigou's Law). Matsuyama (2015, 2018) considers an even more general class of isoelastically nonhomothetic CES preferences, which allow to decouple the effects generated by income elasticity differences and those generated by price elasticity differences. As put forward by Bertoletti and Etro (2018) and Fally (2018), the CES preferences used by Matsuyama $(2015,2018)$ lead, similar to the Gorman-Pollak form preferences considered by Bertoletti and Etro (2017), to a "generalized separable" demand system, which has the nice property that other prices enter the demand functions through a common price index (see Pollak, 1972). Neary et al. (2017) introduce a demand system for which the elasticity of marginal revenue with respect to total revenue is constant. While having no direct link to other demand systems, it has the interesting property to be dual to the demand system derived from PIGL preferences in Neary and Mrázová (2017).

${ }^{6}$ Foellmi et al. (2018) consider a model with hierarchical ' $0-1$ ' preferences and consumption indivisibilities to shed light on the role of per-capita income differences for explaining 'export zeros' observed in the world trade matrix. Wheras similar to Matsuyama (2000), their preferences allow for aggregation of consumer demand over heterogeneous households, they do not elaborate on income dispersion within countries.
} 
to provide a reasoning for the empirical observation that richer countries export goods of higher quality (see Hallak, 2010). Using PIGL preferences, we aggregate demand of heterogeneous households relying on a representative consumer and complement previous work on how differences in the level and/or dispersion of per-capita income shape trade in an open economy, by emphasizing the intensive margin through differences in the consumption level of luxuries.

Employing a mechanism of rent sharing, our model also contributes to a sizable literature dealing with firm-level wage setting in models of international trade. Recent examples to this literature include Davidson et al. (2008), Egger and Kreickemeier (2009, 2012), Helpman et al. (2010), Felbermayr et al. (2011), and Amiti and Davis (2012). Relying on individual bargaining between firms and a continuum of workers in a home-market model with two sectors of production makes the analysis in this paper akin to Helpman and Itskhoki (2010). In contrast to them, we consider homogeneous producers, because firm heterogeneity of the Melitz (2003)-type would complicate the analysis but not affect our results. Furthermore, we assume that rent sharing only exists in one sector, acknowledging the rich evidence on (persistent) inter-industry pay gaps (see Krueger and Summers, 1988; Blanchflower et al., 1996; Katz and Autor, 1999). Associating the sector featuring rent sharing with the sector producing luxuries captures the widespread view that employer characteristics are important determinants of these pay gaps (see Dickens and Katz, 1987; Abowd et al., 2012). Finally, we abstract from search frictions and assume that workers who do not find a job in firms producing luxuries are employed in the production of necessities at the market-clearing wage (see Bastos and Kreickemeier, 2009). We make this assumption, because we are not interested in employment effects per se, but want to shed light on how the reallocation of labor between sectors offering different wages alters the welfare effects of trade in a setting with nonhomothetic preferences.

The remainder of the paper is organized as follows. In Section 2, we set up the basic structure of our model and discuss the closed economy equilibrium. In Section 3, we study trade between two countries that are symmetric in all respects, except for the level and/or dispersion of per-capita income. There, we also discuss how differences in the level and/or dispersion of per-capita income affect trade structure and welfare in the open economy. In Section 4, we consider two extensions, in which we allow for positive assortative matching of workers featuring high effective labor supply with firms in the sector of luxuries and shed light on the differences between demand- and supply-side asymmetries. Section 5 concludes with a summary of our results.

\section{The closed economy}

We consider a static economy that is populated by a continuous set $\mathcal{H}$ of single-person households with Lebesgue measure $H$. In their role as workers, households inelastically supply labor input for the production of goods. Effective labor supply is household-specific and distributed over interval $[\underline{\lambda}, \bar{\lambda}]$ according to a continuously differentiable cumulative distribution function $L(\lambda)$. Ex ante differences in $\lambda$ are an important factor of ex post differences in household income and consumption expenditures. Assuming that preferences do not have Gorman form, both the level and dispersion of income are decisive for the 
aggregate demand for two types of goods: necessities, $n$, which are homogeneous, and luxuries, $\ell$, which are differentiated. However, the link between effective labor supply and household income is exacerbated by a price distortion in the labor market that makes wages sector-specific.

\subsection{Preferences and household consumption}

To establish a link between the distribution of household expenditures and aggregate demand, we consider price-independent generalized linear (so-called "PIGL") preferences introduced by Muellbauer (1975, 1976), which can be represented by an indirect utility function of the following form

$$
v\left(\mathbf{P}, e^{i}\right)=\frac{1}{\varepsilon}\left[\frac{e^{i}}{a(\mathbf{P})}\right]^{\varepsilon}+b(\mathbf{P}),
$$

where $\mathbf{P}$ is a price vector, $e^{i}$ is expenditure of household $i$ and $\varepsilon$ is a constant. The preferences specified in Eq. (1) do not entail an aggregation problem, because they allow to define a representative expenditure level such that a household with this expenditure level has the same value (expenditure) shares of consumption as the aggregate economy. ${ }^{7}$ We consider a subclass of PIGL preferences and assume that households have preferences over two goods, which are represented by an indirect utility function of the following form:

$$
v\left(P_{n}, P_{\ell}, e^{i}\right)=\frac{1}{\varepsilon}\left(\frac{e^{i}}{P_{\ell}}\right)^{\varepsilon}-\frac{\beta}{\varepsilon}\left(\frac{P_{n}}{P_{\ell}}\right)^{\varepsilon}
$$

where $P_{n}, P_{\ell}$ are prices for goods $n$ and $\ell$, respectively, and $\varepsilon, \beta \in(0,1)$ is assumed. As explained by Boppart (2014) and formally shown in the Appendix, in contrast to more general forms of PIGL preferences, Eq. (2) has a closed form representation of the direct utility function, which proves to be useful for the computation of a proper price index if one of the goods is a composite of differentiated varieties that are sold under imperfect competition (see below). In the limiting cases of $\varepsilon$, the preferences in Eq. (2) correspond to two specifications widely used in the literature. If $\varepsilon \rightarrow 0$ preferences are CobbDouglas and therefore homothetic, delivering an indirect utility function of $v\left(P_{n}, P_{\ell}, e^{i}\right)=\ln \left[\frac{e^{i}}{P_{n}^{\beta} P_{\ell}^{1-\beta}}\right]$. If $\varepsilon \rightarrow 1$, preferences are quasilinear and therefore nonhomothetic, delivering an indirect utility function of $v\left(P_{n}, P_{\ell}, e^{i}\right)=\frac{e^{i}}{P_{\ell}}-\beta \frac{P_{n}}{P_{\ell}}$.

Applying Roy's identity to the indirect utility in Eq. (2), we can derive Marshallian demand functions

\footnotetext{
${ }^{7}$ The term of generalized linearity has been introduced by Muellbauer (1975) to emphasize that the preferences are more general than the Gorman class which features consumption levels that are linear in expenditures, thereby making the value shares of consumption independent of the overall expenditure level. This property does not extend to other preference classes. However, generalized linear preferences accord with the weaker condition that the ratio of marginal value shares of any two goods are independent of the overall expenditure level. The notion of price independency is used by Muellbauer (1975) to express that the representative expenditure level, for which an individual household chooses the same value shares of consumption as the aggregate economy, is the same for all permissible prices.
} 
for $X_{n}^{i}$ and $X_{\ell}^{i}$ according to

$$
X_{n}^{i}=\beta\left(\frac{e^{i}}{P_{n}}\right)^{1-\varepsilon} \quad \text { and } \quad X_{\ell}^{i}=\frac{e^{i}}{P_{\ell}}\left[1-\beta\left(\frac{e^{i}}{P_{n}}\right)^{-\varepsilon}\right],
$$

respectively. The Engel curve of good $n$ is concave, making this good a necessity with its value share of consumption decreasing in the expenditure level. In contrast, the Engel curve for good $\ell$ is convex, making this good a luxury with its value share of consumption increasing in the expenditure level. In the limiting cases of $\varepsilon \rightarrow 0$ and $\varepsilon \rightarrow 1$ preferences have Gorman form and Engel curves are therefore linear in the expenditure level. To ensure that both goods are purchased by household $i$, it must be true that $e^{i} / P_{n}>\beta^{1 / \varepsilon}$ and we impose a parameter constraint below that establishes this result.

That Engel curves for necessities and luxuries are differently shaped is the result of assuming that the respective goods enter the utility function asymmetrically. This asymmetry is justified in our model, because we assume that necessities are homogeneous, whereas luxuries are differentiated and can be aggregated to the composite discussed above according to

$$
X_{\ell}^{i}=\left[\int_{\omega \in \Omega} x_{\ell}^{i}(\omega)^{\frac{\sigma-1}{\sigma}} d \omega\right]^{\frac{\sigma}{\sigma-1}}
$$

where $\sigma>1$ is the constant elasticity of substitution between the differentiated varieties $x_{\ell}^{i}(\omega)$ from set $\Omega$. The price corresponding to the composite $X_{\ell}^{i}$ is an index of the prices of differentiated varieties, $p_{\ell}(\omega)$, and it is defined by the condition that $P_{\ell} X_{\ell}^{i}$ is equal to the household's overall expenditures for luxuries, $\int_{\omega \in \Omega} p_{\ell}(\omega) x_{\ell}^{i}(\omega) d \omega$. As formally shown in the Appendix, the respective price index features constant elasticity and is given by $P_{\ell} \equiv\left[\int_{\omega \in \Omega} p_{\ell}(\omega)^{1-\sigma} d \omega\right]^{\frac{1}{1-\sigma}}$. Using Roy's identity, we can then derive household demand for a single variety of the luxury good, $\omega$, according to

$$
x_{\ell}^{i}(\omega)=\frac{e^{i}}{P_{\ell}}\left(\frac{p_{\ell}(\omega)}{P_{\ell}}\right)^{-\sigma}\left[1-\beta\left(\frac{e^{i}}{P_{n}}\right)^{-\varepsilon}\right] .
$$

Aggregating over all households, gives market demand functions

$$
\begin{aligned}
X_{n} & =\int_{0}^{H} X_{n}^{i} d i=\beta \frac{H \bar{e}}{P_{n}}\left(\frac{\bar{e}}{P_{n}}\right)^{-\varepsilon} \psi, \\
x_{\ell}(\omega) & =\int_{i \in \mathcal{H}} x_{\ell}^{i}(\omega) d i=\frac{H \bar{e}}{P_{\ell}}\left(\frac{p_{\ell}(\omega)}{P_{\ell}}\right)^{-\sigma}\left[1-\beta\left(\frac{\bar{e}}{P_{n}}\right)^{-\varepsilon} \psi\right],
\end{aligned}
$$

where $\bar{e} \equiv H^{-1} \int_{i \in \mathcal{H}} e^{i} d i$ is the average expenditure level of households and $\psi \equiv H^{-1} \int_{i \in \mathcal{H}}\left(e^{i} / \bar{e}\right)^{1-\varepsilon} d i$ is a dispersion index that is defined on the unit interval and captures how the distribution of household expenditures affects the value shares of consumption. Since the Engel curve for necessities is concave, a more egalitarian distribution of expenditures, captured by a higher value of $\psi$, increases aggregate demand for necessities. The opposite is true for luxuries, which feature convex Engel curves. The dispersion index 
reaches a maximum level of one if the distribution of expenditures is egalitarian. An outcome with $\psi=1$ is also reached if the distribution of household expenditure is irrelevant for aggregate demand because Engel curves are linear, as in the limiting cases of $\varepsilon \rightarrow 0$ and $\varepsilon \rightarrow 1$.

\subsection{Technology and the firms' problem}

The technology to produce necessities is linear in labor input and we assume that one unit of labor produces one unit of output. Firms producing necessities enter the market at zero cost, hire labor input at a common wage rate $w$, and sell their output under perfect competition. This establishes $w=P_{n}$. Production of luxuries requires the creation of workplaces at the costs of one unit of necessities for each labor input employed. One unit of labor input used in a workplace produces one unit of output. To start production firms must develop a blueprint, which comes at the cost of $f$ units of necessities and gives them access to a unique variety, which they can sell under monopolistic competition.

Workers are free to move between sectors up to the point where all workplaces in the sector of luxuries are filled. Then, in each workplace workers and firms form a bilateral monopoly and they distribute the production surplus under Stole and Zwiebel (1996) bargaining. ${ }^{8}$ Hiring and wage setting in the sector of luxuries can be understood as a two-stage process and solved through backward induction. Looking first at the bargaining problem, we can note that its solution is characterized by two conditions: a splitting rule, determining how the production surplus achieved by an agreement is distributed between the bargaining parties; and an aggregation rule, describing how infra-marginal production surpluses add up to the firm's overall surplus from multilateral bargaining with all of its workers. The bargaining problem considered here is exacerbated by the heterogeneity of workers in their effective labor supply. To facilitate the analysis we assume for now that the number of different worker types employed by the firm is discrete and given by $J$, where firm index $\omega$ is suppressed because the hiring and bargaining problem is the same for all producers.

The mass of employees of type $j$ is $N_{j}$ and the firm's overall surplus from multilateral bargaining with a mass of $N \equiv \sum_{j=1}^{J} N_{j}$ workers is given by

$$
\pi=\int_{0}^{N} \mu(\nu \mid N) \hat{r}(\nu \mathbf{s}) d \nu
$$

where $s_{j}$ is calculated as a product of the type-specific effective labor supply $\lambda_{j}$ and the pre-determined fraction of employed workers of type $j, N_{j} / N$, while $\mathbf{s}$ is the set of resulting $s_{j}$-values: $\mathbf{s} \equiv\left\{s_{1}, \ldots, s_{J}\right\}$. Furthermore, $\hat{r}(\nu \mathbf{s})=D^{\frac{1}{\sigma}} Q(\nu \mathbf{s})^{1-\frac{1}{\sigma}}$ are revenues achieved for employment level $\nu, D \equiv H \bar{e}(1-$ $\left.\beta\left(\bar{e} / P_{n}\right)^{-\varepsilon} \psi\right) / P_{\ell}^{1-\sigma}$ is a common demand shifter, $Q(\cdot)$ is a function determining how the different types

\footnotetext{
${ }^{8}$ It has been recently pointed out by Bruegemann et al. (2018) that the microeconomic foundation of the Stole and Zwiebel (1996) bargaining protocol does not give wage and profit profiles that coincide with the Shapley values. However, relying on a Rolodex Game instead of the non-cooperative game put forward by Stole and Zwiebel, one can restore equivalence of the bargaining outcome with the Shapley values.
} 
of labor are aggregated in the production process, ${ }^{9}$ and

$$
\mu(\nu \mid N) \equiv \frac{\eta}{\nu}\left(\frac{\nu}{N}\right)^{\eta}
$$

is a probability measure that depends on the firm's relative bargaining power $\eta>0$ and determines the fraction of infra-marginal production surplus the firm can acquire in its wage negotiations with workers. Solving the integral in Eq. (8) gives

$$
\pi=\frac{\eta \sigma}{\eta \sigma+\sigma-1} D^{\frac{1}{\sigma}}\left(\sum_{j=1}^{J} \lambda_{j} N_{j}\right)^{1-\frac{1}{\sigma}}=\frac{\eta \sigma}{\eta \sigma+\sigma-1} \hat{r}(N \mathbf{s})
$$

where the first equality sign uses the assumption that the labor input of different worker types is perfectly substitutable, so that $Q(\nu \mathbf{s})=\nu \sum_{j=1}^{J} \lambda_{j} N_{j} / N$.

Since workers forfeit their chance to move to the other sector when accepting the job offer of a firm producing luxuries, they give up their outside income opportunities from employment elsewhere. Therefore, the splitting rule determining how to distribute the production surplus between the firm and its workers can be expressed as

$$
\frac{\partial \pi}{\partial N_{j}}=\eta \hat{w}_{\ell}^{j}
$$

where $\hat{w}_{\ell}^{j}$ is labor income of a worker with effective labor supply $\lambda_{j}$. Eqs. (10) and (11) establish the intuitive result that the wage per unit of labor input, $\hat{w}_{\ell}^{j} / \lambda_{j}$, is the same for all workers, irrespective of their effective labor supply: $\hat{w}_{\ell}^{j} / \lambda_{j} \equiv w_{\ell}$. Taking stock, we can summarize the solution to the firm's bargaining problem by the two equations

$$
\pi=\kappa r, \quad \frac{\partial \pi}{\partial q_{\ell}}=\frac{\sigma-1}{\sigma} \frac{\kappa r}{q_{\ell}}=\eta w_{\ell}
$$

where $q_{\ell} \equiv \sum_{j=1}^{J} \lambda_{j} N_{j}$ denotes total labor input of the firm, $r \equiv D^{\frac{1}{\sigma}} q_{\ell}^{1-\frac{1}{\sigma}}$ gives revenues as a function of labor input, $q_{\ell}$ (instead of the number of employed workers $N$ ), and $\kappa \equiv \eta \sigma /(\eta \sigma+\sigma-1)<1$ is the constant fraction of revenues accrued by the firm in the wage bargaining with workers, which is increasing in the firm's relative bargaining power $\eta .^{10}$

Equipped with Eq. (12), we can now determine the solution to the firm's hiring problem. Recollecting from above that firms have to invest $f$ units of necessities to start production and one unit of necessities to install workplace capacity for each labor input, this solution is found by maximizing $\Pi \equiv \pi-P_{n} q_{\ell}-P_{n} f$

\footnotetext{
${ }^{9}$ Under non-increasing returns to scale at the firm level, we have $Q^{\prime}(\cdot)>0, Q^{\prime \prime}(\cdot) \leq 0$ and thus $\int_{0}^{N} \hat{r}(\nu \mathbf{s})-\hat{r}(N \mathbf{s}) d \nu \geq 0$.

${ }^{10}$ To determine the solution of wage bargaining for a continuous set of labor types, we can first consider a symmetric $J$ division of the support of effective labor supply $[\underline{\lambda}, \bar{\lambda}]$ and denote the density of effective labor supplies on the respective subdivisions by $\ell\left(\lambda_{j}\right)$. This establishes the Riemann sum: $\sum_{1}^{J} \lambda_{j} \ell\left(\lambda_{j}\right) \Delta \lambda_{j}$, with $\Delta \lambda_{j} \equiv \lambda_{j}-\lambda_{j-1}$. Taking the limit, then gives $\lim _{J \rightarrow \infty} \sum_{j=1}^{J} \lambda_{j} \ell\left(\lambda_{j}\right) \Delta \lambda_{j}=\int_{\underline{\lambda}}^{\bar{\lambda}} \lambda d L(\lambda)$, where $\ell(\lambda)=L^{\prime}(\lambda)=d L(\lambda) / d \lambda$ has been considered.
} 
with respect to $q_{\ell}$. Since firms face the same cost for each unit of labor input, they are indifferent between all applicants and hire a workforce whose composition mirrors the economy-wide distribution of effective labor supply. ${ }^{11}$ The first-order condition for the firm's profit-maximizing $q_{\ell}$ choice is given by

$$
\frac{d \Pi}{d q_{\ell}}=\frac{\sigma-1}{\sigma} \frac{\kappa r}{q_{\ell}}-P_{n}=0
$$

Substituting Eq. (12) and accounting for the definition of profits, then gives the outcome of hiring and wage-setting for firms producing luxuries:

$$
w_{\ell}=\alpha P_{n}, \quad \Pi=\frac{\kappa r}{\sigma}-P_{n} f
$$

where $\alpha \equiv \eta^{-1}$ gives the relative bargaining power of workers in the wage negotiation with the firm. Eq. (14) has been derived under the assumption that firms producing luxuries can attract the intended mass of applicants at a wage rate $\alpha P_{n}$. This requires that employment at these firms promises a wage at least as high as $w$ in order to convince workers to accept the job offer. Hence, the wage paid in the sector of necessities establishes a participation constraint for workers seeking employment in the sector of luxuries, so that $\alpha \geq 1$ is needed to ensure that at least some of the workplaces installed by firms producing luxuries are filled. If $\alpha>1$, jobs in the sector of luxuries promise a wage premium, and hence every household prefers working there. This outcome, which we consider in the subsequent analysis, can only be consistent with diversified production in both sectors, if some of the workers are not hired by luxury producers and therefore are forced to move to the production of necessities. Of course, these workers want to underbid $w_{\ell}$. However, underbidding cannot be successful if wage offers at stage one are not contractible. Without a binding contract, successful applicants will rationally deviate from their initial offer to accept a wage discount and opt for the highest wage they can achieve in the bargaining with the firm, exploiting the protection from the bilateral monopoly that is established after the workplaces have been filled. Hence, our model generates wage differences due to a market imperfection that is rooted in information asymmetry and the irreversibility of the firm's hiring decision. Since firms can freely enter the sector of luxuries, they must make zero profits in equilibrium, which establishes the zero-profit condition $\kappa r=\sigma P_{n} f$, according to Eq. (14).

\subsection{The general equilibrium}

Household consumption expenditures are equal to labor income and heterogeneous for two reasons: due to ex ante (and thus exogenous) differences in effective labor supply; and due to differences in the wages paid by the sectors producing necessities and luxuries. The worker achieving the lowest income has an ability level of $\underline{\lambda}$ and is employed in the sector producing necessities, yielding an expenditure level of

\footnotetext{
${ }^{11}$ The assumption that firms have to pay the same workplace installment costs for each unit of labor input facilitates our analysis. Under the alternative assumption that firms install the same workplace capacity for each employee, irrespective of her effective labor supply, our model would generate an incentive for screening the applicants in order to improve the average composition of production workers (see Helpman et al., 2010). We discuss this case in an extension of our model.
} 
$\underline{\lambda} w$. Since the sector of necessities pays a wage of $w=P_{n}$, the minimum permissible expenditure level necessary for consuming necessities as well as luxuries then establishes a threshold level for effective labor supply, $\beta^{1 / \varepsilon}$, that must be passed in order to ensure that even the poorest households attribute some of their expenditures to the consumption of luxuries. To exclude corner solutions and to focus on changes along the intensive margin of consumption, we assume throughout our analysis that $\underline{\lambda}>\beta^{1 / \varepsilon}$.

Nominal per-capita (labor) income is equal to average household expenditures and given by

$$
\bar{e}=w\left(1-h_{\ell}\right) \int_{\underline{\lambda}}^{\bar{\lambda}} \lambda d L(\lambda)+w_{\ell} h_{\ell} \int_{\underline{\lambda}}^{\bar{\lambda}} \lambda d L(\lambda)=w \Lambda\left[1+h_{\ell}(\alpha-1)\right],
$$

where $\Lambda \equiv \int_{\underline{\lambda}}^{\bar{\lambda}} \lambda d L(\lambda)$ is the average effective labor supply of households and $h_{\ell}$ is the fraction of workers employed in the production of luxuries, receiving wage premium $\alpha$. The dispersion index, measuring how the distribution of household expenditures affects aggregate consumer demand, can be computed according to

$$
\psi=\left(\frac{w}{\bar{e}}\right)^{1-\varepsilon}\left[1+h_{\ell}\left(\alpha^{1-\varepsilon}-1\right)\right] \int_{\underline{\lambda}}^{\bar{\lambda}} \lambda^{1-\varepsilon} d L(\lambda)=\frac{1+h_{\ell}\left(\alpha^{1-\varepsilon}-1\right)}{\left[1+h_{\ell}(\alpha-1)\right]^{1-\varepsilon}} \psi_{\lambda},
$$

where $\psi_{\lambda} \equiv \int_{\underline{\lambda}}^{\bar{\lambda}}(\lambda / \Lambda)^{1-\varepsilon} d L(\lambda)$ is a measure of the dispersion of effective labor supply. In the limiting case of $\alpha=1$, producers of luxuries pay the market clearing wage $w_{\ell}=w$, implying that the dispersion of labor income in Eq. (16) is pinned down and fully determined by the exogenous dispersion of effective labor supply, $\psi_{\lambda}$. If $\alpha>1$, firms producing luxuries pay a wage premium, which amplifies the dispersion of labor income: $\psi<\psi_{\lambda}$. The value of the dispersion index depends in a nonmonotonic way on the share of workers employed for producing luxuries, $h_{\ell}{ }^{12}$

To determine the fraction of workers receiving a wage premium, $h_{\ell}$, we can combine two preliminary results from our analysis. First, as a consequence of constant markup pricing the wage bill paid by firms is a constant fraction $\frac{\sigma-1}{\sigma} \kappa=\frac{\sigma-1}{\sigma+\alpha(\sigma-1)}$ of their revenues. This generates a positive link between the share of workers and the mass of firms producing luxuries:

$$
h_{\ell} H \Lambda w=\frac{\sigma-1}{\sigma} \kappa M r .
$$

Since we have assumed that workers who do not find employment in the production of luxuries can move to the sector of necessities at zero cost, there is no involuntary unemployment in our model, and the fraction of workers employed in the production of necessities is therefore given by $1-h_{\ell}$. The second preliminary result is the goods market clearing condition for luxuries, which can be derived from Eq. (7)

\footnotetext{
${ }^{12}$ In the limiting case $h_{\ell}=0$, there is no one employed in the sector of luxuries making wage premium $\alpha$ irrelevant and establishing $\psi=\psi_{\lambda}$. In the limiting case of $h_{\ell}=1$ all workers are employed in the production of luxuries and receive the wage premium, again resulting in $\psi=\psi_{\lambda}$. Dispersion index $\psi$ is u-shaped and reaches a minimum at

$$
h_{\ell}^{\text {min }} \equiv \frac{(1-\varepsilon)(\alpha-1)-\left(\alpha^{1-\varepsilon}-1\right)}{\varepsilon(\alpha-1)\left(\alpha^{1-\varepsilon}-1\right)} \in(0,1) .
$$
}


according to

$$
H \Lambda w\left[1-\beta \Lambda^{-\varepsilon} \psi_{\lambda}\right]+h_{\ell} H \Lambda w \frac{\sigma}{\sigma-1} \frac{B}{\kappa}=M r
$$

where $B \equiv \frac{\sigma-1}{\sigma} \kappa\left[(\alpha-1)-\left(\alpha^{1-\varepsilon}-1\right) \beta \Lambda^{-\varepsilon} \psi_{\lambda}\right]$, with $\lim _{\alpha \rightarrow 1} B=0, d B / d \alpha>0$, and $\lim _{\alpha \rightarrow \infty} B=$ 1 , captures how the existence of a wage premium in the sector of luxuries augments economy-wide expenditures for luxuries. In the limiting case of $\alpha=1$ labor income does not depend on the allocation of workers and the market size for luxuries is therefore pinned down by the level and dispersion of effective labor supply. This makes $M$ in Eq. (18) independent of $h_{\ell}$. For $\alpha>1$, employment in the sector of luxuries promises a wage premium, so that a higher fraction of workers allocated to the production of luxuries provides a positive effect on the market size and thus a stimulus for firm entry in this sector. In this case, the goods market clearing condition in Eq. (18) establishes a positive link between $h_{\ell}$ and $M$. Substituting zero-profit condition $\sigma P_{n} f=\kappa r$, Eqs. (17) and (18) can be combined to get explicit solutions for the mass of firms and the fraction of workers producing luxuries:

$$
M=\frac{\kappa}{1-B} \frac{H \Lambda\left[1-\beta \Lambda^{-\varepsilon} \psi_{\lambda}\right]}{\sigma f}, \quad h_{\ell}=\frac{\sigma-1}{\sigma} \frac{\kappa}{1-B}\left[1-\beta \Lambda^{-\varepsilon} \psi_{\lambda}\right]
$$

Both a higher average level of effective labor supply, (a higher $\Lambda$ ), and a lower dispersion of this supply, (a higher $\psi_{\lambda}$ ), cause an increase in $M$ and $h_{\ell}$, because wealthier households attribute a higher fraction of their expenditures to luxuries if preferences do not have Gorman form. Furthermore, noting $\frac{\kappa}{1-B}=\left\{1+\frac{\sigma-1}{\sigma}\left[1+\left(\alpha^{1-\varepsilon}-1\right) \beta \Lambda^{-\varepsilon} \psi_{\lambda}\right]\right\}^{-1}<1$, it follows from Eq. (19) that a higher wage premium $\alpha$ reduces both the mass of firms and the fraction of workers producing luxuries. This is intuitive, because a higher $\alpha$ reflects a stronger bargaining power of workers and is therefore associated with a lower fraction of revenues accrued by firms in their wage negotiations, making production of luxuries less attractive for them. However, the finding that a lower fraction of workers is employed in the sector producing luxuries does not imply that less labor income is generated there. The increase in wage premium $\alpha$ that is responsible for the fall in $h_{\ell}$ implies a wage stimulus for those workers who continue to produce luxuries. Differentiating $h_{\ell}(\alpha-1)$ reveals that a higher wage premium $\alpha$ leads to higher per-capita income $\bar{e}$ and therefore increases economy-wide expenditures for luxuries, $H \Lambda w\left[1-\beta \Lambda^{-\varepsilon} \psi_{\lambda}\right] /(1-B)$. The positive market size effect from higher labor income is counteracted and dominated by a labor cost increase for firms producing luxuries, so that higher economy-wide expenditures are consistent with lower levels of $M$ and $h_{\ell}$. Using Eq. (19) and the constant markup-pricing rule $p_{\ell}=\frac{\sigma}{\sigma-1} \frac{w}{\kappa}$ in the definition of the price index of luxuries, we can compute

$$
P_{\ell}=\frac{\sigma}{\sigma-1} \frac{w}{\kappa}\left[\frac{\kappa}{1-B} \frac{H \Lambda\left(1-\beta \Lambda^{-\varepsilon} \psi_{\lambda}\right)}{\sigma f}\right]^{\frac{1}{1-\sigma}} .
$$

A higher wage premium $\alpha$ exerts two reinforcing effects on price index $P_{\ell}$. It increases labor costs and therefore the price charged by firms producing luxuries, $p_{\ell}$, and it induces firm exit and thus reduces the mass of available varieties, $M$, thereby further increasing $P_{\ell}$. 


\subsection{Welfare in the closed economy}

We postulate a Bergson-Samuelson social welfare function that is equal to the average indirect utility of households. Accounting for Eq. (2), social welfare is then given by ${ }^{13}$

$$
V\left(P_{n}, P_{\ell}, \bar{e}, \hat{\psi}\right) \equiv \frac{1}{\varepsilon}\left(\frac{P_{n}}{P_{\ell}}\right)^{\varepsilon}\left[\left(\frac{\bar{e}}{P_{n}}\right)^{\varepsilon} \hat{\psi}-\beta\right]
$$

where $\hat{\psi} \equiv H^{-1} \int_{i \in \mathcal{H}}\left(e^{i} / \bar{e}\right)^{\varepsilon} d i$ is an inverse measure of income dispersion that is defined on the unit interval and linked to the dispersion of effective labor supply, $\hat{\psi}_{\lambda} \equiv \int_{\underline{\lambda}}^{\bar{\lambda}}(\lambda / \Lambda)^{\varepsilon} d L(\lambda)$, according to $\hat{\psi}=\hat{\psi}_{\lambda}\left[1+h_{\ell}\left(\alpha^{\varepsilon}-1\right)\right] /\left[1+h_{\ell}(\alpha-1)\right]^{\varepsilon}$. The two dispersion indices $\psi$ and $\hat{\psi}$ are closely related but nonetheless different, except for the limiting case of $\varepsilon=1 / 2$. For a welfare analysis, it is useful to distinguish direct effects through changes in the average level and dispersion of nominal income from indirect effects through adjustments in the price index of luxuries caused by these changes. Furthermore, to facilitate our analysis and to distinguish the different effects that price distortions in the product and labor market have in our setting, we first look at the limiting case of $\alpha=1$, which yields $\bar{e}=\Lambda w$, $\psi=\psi_{\lambda}$, and $\hat{\psi}=\hat{\psi}_{\lambda}$. For this limiting case, a higher nominal level of per-capita income is rooted in a higher average level of effective labor supply and has unambiguously positive welfare effects, because it allows for additional purchases of necessities and luxuries at given prices and, at the same time, lowers the price index of luxuries through firm entry.

In contrast, the welfare effect of a higher nominal income dispersion, which is due to a higher dispersion of effective labor supply, is a priori not clear. On the one hand, the welfare function in Eq (21) features a social aversion to income inequality, and a transfer from a wealthier household to a poorer one that does not change their income ranking reduces inequality and therefore increases social welfare (cf. Dalton, 1920). ${ }^{14}$ On the other hand, the incentive to harmonize income is counteracted by a distortion of the resource allocation that exists because households devote part of their expenditures to necessities, which makes, all other things equal, the mass of firms entering inefficiently small from a social planner's point of view. As pointed out by Dhingra and Morrow (2016) this allocational inefficiency exists because the markups charged in the two industries differ. Introducing a transfer from poor to rich people would increase demand for luxuries and therefore provide a (partial) remedy for the misallocation of resources, leading to a fall in the price index of luxuries.

To gain further insights into the relative strength of the two counteracting effects, we can evaluate the

\footnotetext{
${ }^{13}$ Giving equal weight to all households, we take a utilitarian perspective. Social welfare under this perspective differs from the indirect utility of the household with a representative expenditure level. The (price-invariant) representative level of expenditure is defined by Muellbauer (1975) to ensure that a household with this expenditure level has the same value shares of consumption as the aggregate economy and it is given by $e_{r} \equiv \bar{e} \psi^{-1 / \varepsilon}$, according to Eqs. (3) and (6). Substituting into Eq. (2) establishes $v\left(P_{n}, P_{\ell}, e_{r}\right)=\frac{1}{\varepsilon}\left(\frac{P_{n}}{P_{\ell}}\right)^{\varepsilon}\left[\left(\frac{\bar{e}}{P_{n}}\right)^{\varepsilon} \psi^{-1}-\beta\right]$ and, due to $\psi, \hat{\psi}<1$, a utility level that is larger than social welfare in Eq. (21). Since the representative consumer from Muellbauer $(1975,1976)$ lacks a normative interpretation, it cannot be used for welfare analysis.

${ }^{14}$ Dispersion index $\hat{\psi}$ is a negative monotonic transformation of the well-known Atkinson (1970) index. In our setting, the evaluation of income inequality is, however, not the result of giving worse-off households higher weights in the welfare function, as suggested by a prioritarian view on distributional justice (cf. Parfit, 1997). Rather, social inequality aversion is the result of non-Gorman form preferences under a utilitarian perspective.
} 
social welfare function $V(\cdot)$ at $\varepsilon=1 / 2$, which establishes $\psi=\hat{\psi}$. Noting further that $\alpha=1$ yields $\bar{e}=\Lambda P_{n}$ and $\psi=\psi_{\lambda}$, the welfare effects of lower income dispersion (a higher $\psi_{\lambda}$ ) are then given by

$$
\frac{d V\left(P_{n}, P_{\ell}, \Lambda P_{n}, \psi_{\lambda}\right)}{d \psi_{\lambda}} \equiv \sqrt{\frac{P_{n}}{P_{\ell}} \frac{\Lambda}{(\sigma-1)^{2}}}\left[2 \sigma-1-\frac{1-(\beta / \sqrt{\Lambda})^{2}}{1-(\beta / \sqrt{\Lambda}) \psi_{\lambda}}\right] .
$$

From Eq. (22), positive welfare effects of lower income dispersion are more likely ceteris paribus if $\sigma$ is large. ${ }^{15}$ This is intuitive, because higher levels of $\sigma$ reduce the price markup charged by monopolistically competitive firms producing luxuries, which lowers the problem of resource misallocation due to distorted market entry. Also, lower income dispersion increases welfare if $\beta$ is sufficiently small. In the limiting case of $\beta \rightarrow 0$ the model degenerates to a one-sector economy, in which only luxuries are produced, making aggregate demand independent of the distribution of income.

If $\alpha>1$ the two counteracting effects described above are augmented by rent sharing between firms and workers in the sector producing luxuries. As outlined above, the existence of a wage premium makes entry less attractive and increases the price index of luxuries, with a negative indirect effect on social welfare. This indirect effect is counteracted by a direct effect on social welfare, which exists, because rent sharing leads to an increase in the average level and dispersion of nominal income. In the limiting case of Cobb-Douglas preferences, it is the first effect that dominates. Since the mass of firms choosing to produce luxuries is already below the social optimum without rent sharing (cf. Benassy, 1996), a further decrease in the mass of firms producing luxuries due to an increase in $\alpha$ is detrimental for social welfare. In the limiting case of quasilinear preferences, firm entry is socially optimal without rent sharing. Since the increase in labor income triggered by rent sharing leads to an equally strong increase in the expenditures for luxuries, the direct and indirect effect cancel, leaving social welfare unaffected. Finally, if preferences do not have Gorman form and Engel curves are therefore nonlinear, we cannot rule out that social welfare is higher with than without rent sharing (see the Appendix).

We complete the discussion of the closed economy by elaborating on a crucial difference between direct and indirect effects regarding the consequences that changes in nominal income have on individual households. Whereas the direct effect of such changes is household-specific, the indirect effect due to adjustments of the price index of luxuries is the same for all households, provided that $\underline{\lambda}>\beta^{1 / \varepsilon}$ induces even the consumer with the lowest income to purchase luxuries. This is a result of indirect utility in Eq. (2) being an isoelastic function of price index $P_{\ell}$ and it has important consequences for the welfare effects of trade in our setting. Households can only be differently affected by trade if moving to the open economy exerts asymmetric effects on nominal income, which is only possible in turn if rent sharing leads to a wage premium in the sector of luxuries.

\footnotetext{
${ }^{15}$ In the limiting case of $\sigma \rightarrow 1$, Eq. (22) yields $d V(\cdot) / d \psi_{\lambda}>,=,<0$ if $\beta>,=,<\Lambda^{1 / 2} \int_{\underline{\lambda}}^{\bar{\lambda}}(\lambda / \Lambda)^{1 / 2} d L(\lambda)$. For $\varepsilon=1 / 2$, condition $\underline{\lambda}>\beta^{1 / \varepsilon}$ gives $\beta<\int_{\underline{\lambda}}^{\bar{\lambda}} \lambda^{1 / 2} d L(\lambda)$ and thus $d V(\cdot) / d \psi_{\lambda}<0$ if $\sigma \rightarrow 1$. In contrast, $d V(\cdot) / d \psi_{\lambda}>0$ holds for sufficiently high levels of $\sigma$.
} 


\section{The open economy}

In the open economy, we consider trade between two countries that are symmetric in all respects, except for the average level and/or dispersion of effective labor supply. ${ }^{16}$ Trade in necessities is free of costs, and hence wage $w$ is the same in the two economies, provided that production remains diversified in both locations. We discuss the parameter domain supporting diversification below. Trade in luxuries is subject to iceberg trade costs, implying that $t^{\frac{1}{\sigma-1}}>1$ units of the good must be shipped in order for one unit to arrive in the foreign country.

Total domestic plus export revenues of firms in the two countries are linked by the zero-profit conditions, $\kappa r=\sigma P_{n} f, \kappa r^{*}=\sigma P_{n} f$, where an asterisk is used to indicate variables of the foreign economy. Since production costs are the same in the two countries, the zero-profit conditions link the differences in the price indices for luxuries to differences in the expenditures for these goods according to

$$
\rho \zeta=\left(\frac{P_{\ell}}{P_{\ell}^{*}}\right)^{\sigma-1}
$$

with

$$
\rho \equiv \frac{1-\beta\left(\Lambda^{*}\right)^{-\varepsilon} \psi_{\lambda}^{*}}{1-\beta(\Lambda)^{-\varepsilon} \psi_{\lambda}} \quad \text { and } \quad \zeta \equiv \frac{1+\frac{\sigma}{\sigma-1} \frac{1}{\kappa} h_{\ell}^{*} B^{*} /\left[1-\beta\left(\Lambda^{*}\right)^{-\varepsilon} \psi_{\lambda}^{*}\right]}{1+\frac{\sigma}{\sigma-1} \frac{1}{\kappa} h_{\ell} B /\left[1-\beta \Lambda^{-\varepsilon} \psi_{\lambda}\right]}
$$

$B^{*}$ and $P_{\ell}^{*}$ are defined in analogy to the respective variables at home. Parameter $\rho \neq 1$ reflects relative differences of the two countries in their expenditures for luxuries that are due to ex ante differences in the average level and/or dispersion of effective labor supply, whereas $\zeta$ captures a magnification $(\zeta>1)$ or diminution $(\zeta<1)$ of these differences due to endogenous reallocations of labor and thus changes in the nominal income of households if $\alpha>1$. The combined term $\rho \zeta$ captures foreign's relative market size for luxuries and, as explained in detail below, it is larger (smaller) than one if $\Lambda^{*}>(<) \Lambda$ and/or $\psi_{\lambda}>(<) \psi_{\lambda}^{*}$.

To determine factor allocation and production structure in a diversification equilibrium, we can rely on the insight from the closed economy, that the constant markup pricing rule establishes a positive link between the fraction of workers and the mass of local firms producing luxuries. For home, the respective link is given by Eq. (17), whereas for foreign an analogous link can be derived according to

$$
h_{\ell}^{*} H \Lambda w=\frac{\sigma-1}{\sigma} \kappa M^{*} r^{*}
$$

where $H \Lambda=H^{*} \Lambda^{*}$ has been considered. A second link between the fraction of workers and the mass of local firms producing luxuries is obtained from the market clearing conditions of luxuries, which for

\footnotetext{
${ }^{16}$ We set $H \Lambda=H^{*} \Lambda^{*}$, because the effects of differences in total labor endowments are well understood from Helpman and Krugman (1985) and because they are similar for homothetic and nonhomothetic preferences.
} 
home and foreign are given by

$$
\begin{aligned}
H \Lambda w\left[1-\beta \Lambda^{-\varepsilon} \psi_{\lambda}\right]+h_{\ell} H \Lambda w \frac{\sigma}{\sigma-1} \frac{1}{\kappa} B & =M r \frac{t}{1+t}+M^{*} r^{*} \frac{1}{1+t}, \\
H \Lambda w\left[1-\beta\left(\Lambda^{*}\right)^{-\varepsilon} \psi_{\lambda}^{*}\right]+h_{\ell}^{*} H \Lambda w \frac{\sigma}{\sigma-1} \frac{1}{\kappa} B^{*} & =M^{*} r^{*} \frac{t}{1+t}+M r \frac{1}{1+t},
\end{aligned}
$$

respectively, where $t /(1+t)$ is the share of revenues that is due to domestic sales and $1 /(1+t)$ is the share of revenues that is due to exports.

Combining Eqs. (17), (25)-(27) and acknowledging $r=r^{*}$, we can solve for three functional relationships between the three endogenous variables $h_{\ell}, h_{\ell}^{*}$, and $\mu \equiv M^{*} / M$ in general equilibrium. The first relationship is obtained from substituting $h_{\ell}$ and $h_{\ell}^{*}$ from Eqs. (17) and (25) into Eqs. (26) and (27), respectively, dividing the two resulting expressions, and solving for $\mu$ :

$$
\mu=\frac{\rho[t-B(1+t)]-1}{t-B^{*}(1+t)-\rho}=\frac{1}{\underline{\rho}(t)} \frac{\rho-\underline{\rho}(t)}{\bar{\rho}(t)-\rho} \equiv \tilde{\mu}(\rho),
$$

with $\underline{\rho}(t)=[t-B(1+t)]^{-1}$ and $\bar{\rho}(t)=t-B^{*}(1+t)$. The link between $\rho$ and $\mu$ established by Eq. (28) is positive, $d \mu / d \rho>0$, and depicted by the upper left panel of Figure 1. The equilibrium value of $\mu$ in Eq. (28) is independent of the realizations of $h_{\ell}, h_{\ell}^{*}$, provided that these realizations support diversified production in the two economies. The permissible range of $\rho$ supporting production of luxuries in both countries is given by interval $(\underline{\rho}(t), \bar{\rho}(t))$. Noting that $\lim _{t \rightarrow \infty} \underline{\rho}(t)=0$ and $\lim _{t \rightarrow \infty} \bar{\rho}(t)=\infty$, we can conclude that an interval of permissible levels of $\rho$ exists if transport costs are sufficiently high. The parameter range supporting production of necessities in both countries is discussed below.

Furthermore, substituting $M r$ from Eq. (17) into Eq. (26) and substituting $M^{*} r^{*}$ from Eq. (25) into Eq. (27), we can solve for

$$
\begin{gathered}
h_{\ell}=\frac{\sigma-1}{\sigma} \kappa \frac{1-\beta \Lambda^{-\varepsilon} \psi_{\lambda}}{[\mu+t] /[1+t]-B} \equiv \tilde{h}_{\ell}(\mu), \\
h_{\ell}^{*}=\frac{\sigma-1}{\sigma} \kappa \frac{1-\beta\left(\Lambda^{*}\right)^{-\varepsilon} \psi_{\lambda}^{*}}{[1+\mu t] /[\mu(1+t)]-B^{*}} \equiv \tilde{h}_{\ell}^{*}(\mu),
\end{gathered}
$$

respectively. Eq. (29) establishes a negative link between the fraction of workers producing luxuries in home, $h_{\ell}$, and firm ratio $\mu: d h_{\ell} / d \mu<0$. This is intuitive, because a higher fraction of firms located abroad implies that fewer workers are employed for the production of luxuries at home. Eq. (30) establishes a positive link between the fraction of workers producing luxuries abroad, $h_{\ell}^{*}$, and firm ratio $\mu: d h_{\ell}^{*} / d \mu>0$. A higher fraction of firms located abroad implies that more workers are hired for the production of luxuries, there. The functional relationships between firm ratio $\mu$ and the fraction of local employment in the sector of luxuries are depicted in the upper right panel of Figure 1. In the lower right panel of Figure 1, we add an additional locus that shows how changes in labor allocation reflected by changes in $h_{\ell}$ and $h_{\ell}^{*}$ are related to changes in the mass of firms producing luxuries in the two economies, 


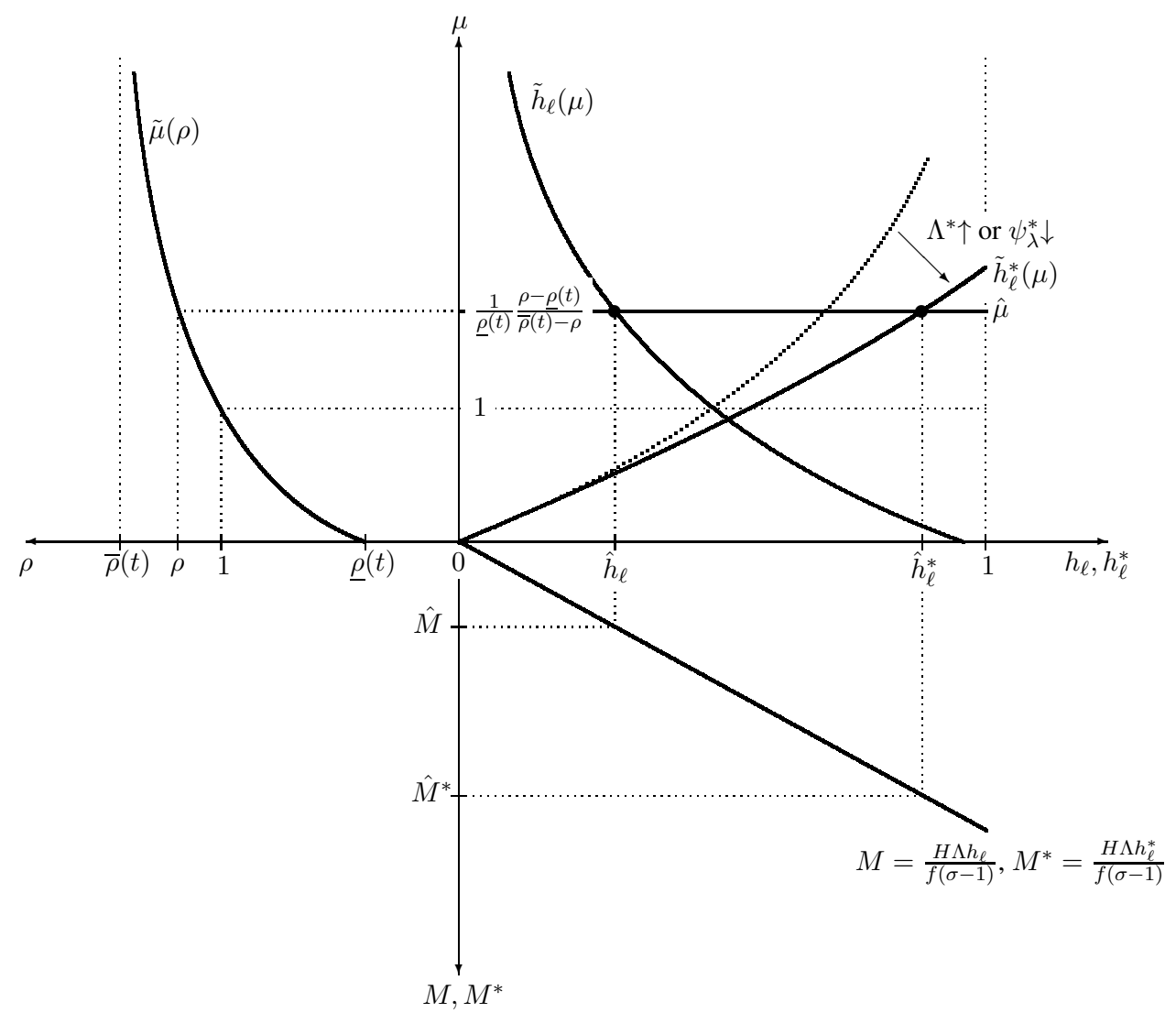

Figure 1: Equilibrium in the open economy for $\rho>1$

$M$ and $M^{*}$. The locus is obtained from substituting zero-profit condition $\kappa r=\sigma P_{n} f$ and $w=P_{n}$ into Eq. (17), and the functional relationship between $M$ and $h_{\ell}$ established by this equation is the same as the functional relationship between $M^{*}$ and $h_{\ell}^{*}$ established by Eq. (25), provided that total labor endowments do not differ in the two economies.

The open economy equilibrium is characterized by the intersection of the negatively sloped locus $\tilde{h}_{\ell}(\mu)$ and the positively sloped locus $\tilde{h}_{\ell}^{*}(\mu)$ with the horizontal $\mu$-line in the upper right panel of Figure 1. In the case of symmetric countries with $\rho=1, \tilde{h}_{\ell}(\mu)$ and $\tilde{h}_{\ell}^{*}(\mu)$ intersect at $\mu=1$, implying that the fraction of workers and the number of firms producing luxuries is the same in the two economies. An increase in the average level or dispersion of effective labor supply abroad $\left(\Lambda^{*}>\Lambda\right.$ or $\left.\psi_{\lambda}^{*}<\psi_{\lambda}\right)$ leads to a higher level of $\rho$, because foreign expenditures for luxuries increase relative to domestic ones. At the same time, the $\tilde{h}_{\ell}^{*}(\mu)$-locus rotates clockwise, because a higher demand for luxuries requires for a given firm ratio $\mu$ higher labor input in order to produce the quantity of luxuries necessary for market clearing. Because a larger fraction of firms chooses to enter the now bigger foreign market after the increase in $\rho$, there is a second-round effect on the fraction of workers producing luxuries, which causes a further expansion in the foreign labor input and a decline in the domestic labor input used for the production of luxuries. This second-round adjustment is captured by movements along the $\tilde{h}_{\ell}(\mu)$-locus and the rotated 
$\tilde{h}_{\ell}^{*}(\mu)$-locus in the upper right panel of Figure 1. From the lower right panel, we furthermore see that the decrease in the fraction of workers induces a decrease in the mass of firms producing luxuries at home, whereas the increase in the fraction of workers leads to an increase in the mass of firms producing luxuries abroad.

From Figure 1, we also see that considering a permissible value of $\rho$ is not sufficient to guarantee diversification of production. A positive production level of necessities in both economies requires in addition that labor allocation respects $h_{\ell}, h_{\ell}^{*}<1$. The formal conditions that guarantee positive production levels of necessities at home and abroad for permissible values of $\rho$ can be derived from substituting Eq. (28) into Eqs. (29) and (30), and they are given by

$$
\begin{aligned}
\kappa \frac{\sigma-1}{\sigma}\left[1-\beta \Lambda^{-\varepsilon} \psi_{\lambda}\right] & <1-B+\frac{\rho(1-B)-\left(1-B^{*}\right)}{\bar{\rho}(t)-\rho}, \\
\kappa \frac{\sigma-1}{\sigma}\left[1-\beta\left(\Lambda^{*}\right)^{-\varepsilon} \psi_{\lambda}^{*}\right] & <1-B^{*}+\frac{\left(1-B^{*}\right)-\rho(1-B)}{\rho / \underline{\rho}(t)-1},
\end{aligned}
$$

respectively (see the Appendix). From the analysis of the closed economy, we know that these two conditions are fulfilled under autarky, which corresponds to the limiting case of $t \rightarrow \infty$. Noting further that $\underline{\rho}^{\prime}(t)<0$ and $\bar{\rho}^{\prime}(t)>0$, we can safely conclude that a diversification equilibrium exists if trade costs are not too small. The impact of higher trade costs on the open economy equilibrium is illustrated in Figure 2.

Differentiating firm ratio $\mu$ with respect to trade cost parameter $t$ gives

$$
\frac{d \mu}{d t}=-\frac{(1+\rho)\left[\rho(1-B)-\left(1-B^{*}\right)\right]}{[\rho-\bar{\rho}(t)]^{2}}
$$

and thus $d \mu / d t>,=,<0$ if $1>=,<\mu$ or, equivalently, $1>,=,<\rho$. This accords with the important insight that the home-market effect is stronger at lower trade costs (see Davis, 1998). In the upper left panel of Figure 2, we see that the change in firm allocation caused by an increase in the trade cost parameter $t$ leads to a counter-clockwise rotation of $\tilde{\mu}(\rho)$ and to an expansion of the permissible range of expenditure ratio $\rho$. For the given level of $\rho>1$, firm ratio $\mu$ decreases if trade cost parameter $t$ increases.

Regarding the impact of higher trade costs on the fraction of workers employed in the production of luxuries, we can first determine the direct effect for a given level of $\mu$. From Eqs. (29) and (30), we can compute $\partial h_{\ell} / \partial t>,=,<0$ and $0>,=,<\partial h_{\ell}^{*} / \partial t$ if $\mu>,=,<1$, with the signs of the derivatives explained by the home-market effect in our model. The direct effect of an increase in $t$ on $h_{\ell}$ and $h_{\ell}^{*}-$ captured by a rotation of loci $\tilde{h}_{\ell}(\mu)$ and $\tilde{h}_{\ell}^{*}(\mu)$ in the upper right panel of Figure 2 - is reinforced by an indirect effect through adjustments in firm allocation - captured by a movement along the now rotated loci. For the considered case of $\rho>1$, higher trade costs unambiguously lead to an increase in the share of workers used for producing luxuries at home and to a decrease in the respective share abroad. The observation that employment for the production of luxuries is reduced in the country that uses a larger fraction of its workforce to produce these goods and the observation that the range of permissible levels of $\rho$ has increased lend support to our previous insight that higher trade costs make an outcome with 


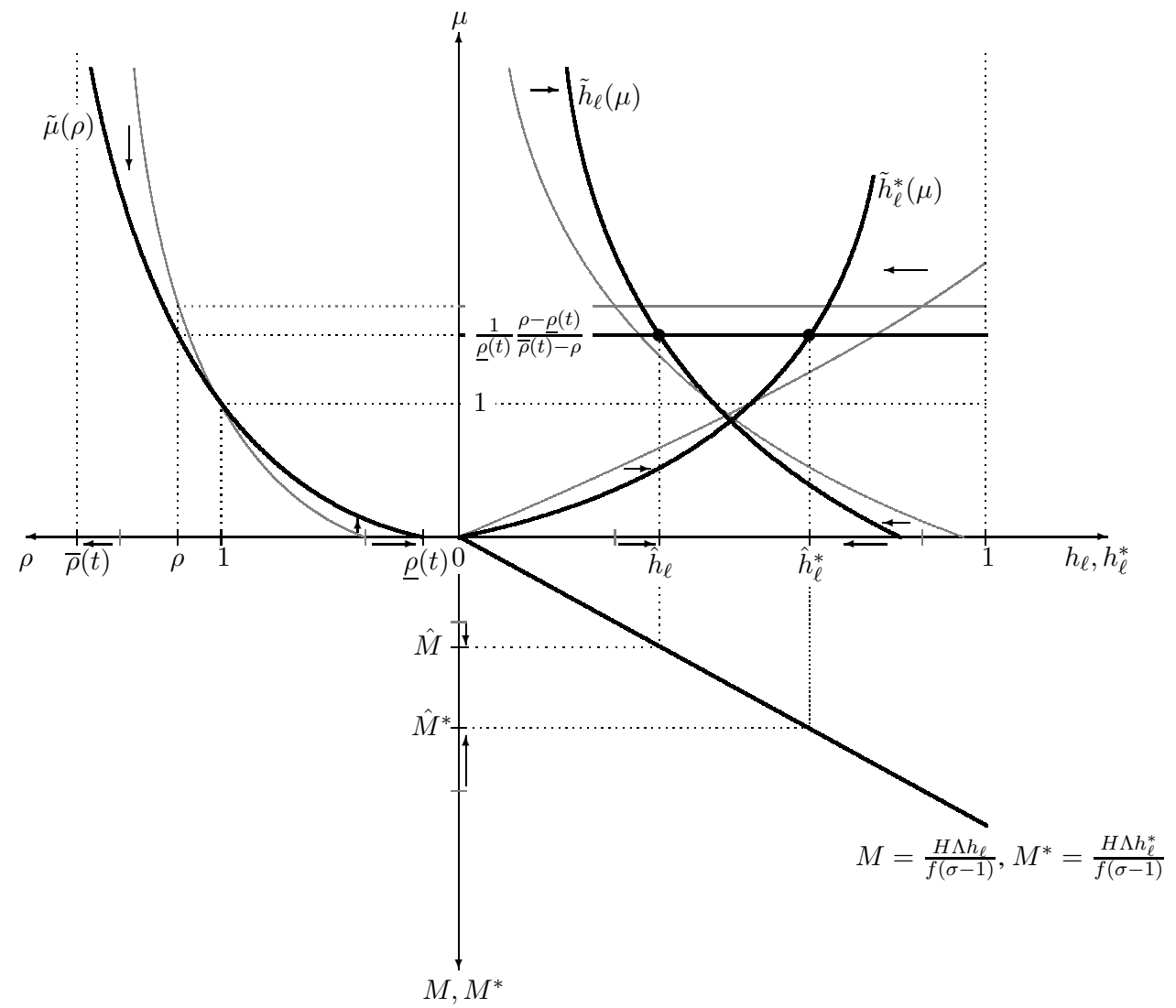

Figure 2: Comparative-static effects of an increase in trade cost parameter $t$

diversified production more likely in the open economy. In the lower right panel of Figure 2, we see that for $\rho>1$ an increase in the fraction of workers producing luxuries in home stimulates firm entry, there. In the foreign country, the decline in the fraction of workers causes a decline in the mass of firms producing luxuries. Firm allocation and production structure have been derived under the assumption that household preferences do not have Gorman form. In the limiting case of Cobb-Douglas preferences, we have $\rho=1$ and thus $h_{\ell}=h_{\ell}^{*}, M=M^{*}$, irrespective of existing differences between the two countries in their average level and/or dispersion of effective labor supply. In the limiting case of quasilinear preferences $\rho \neq 1$ and thus $h_{\ell} \neq h_{\ell}^{*}, M \neq M^{*}$ require differences of the two countries in their average effective labor supply, whereas differences in the dispersion of effective labor supply do not generate asymmetries in the local markets for luxuries, leading to $\rho=1$.

The foreign to domestic firm ratio $\mu$ is instrumental for the trade pattern in the open economy. Employing the zero-profit condition, we can determine home's total exports and imports of luxuries. Accounting 
for $r^{*}=r$, we have

$$
\begin{aligned}
& E X_{\ell}=M \frac{1}{1+t} \frac{\sigma P_{n} f}{\kappa}, \\
& I M_{\ell}=\mu M \frac{1}{1+t} \frac{\sigma P_{n} f}{\kappa}
\end{aligned}
$$

respectively, which shows that home is a net-importer (net-exporter) of luxuries if $\mu>(<) 1$. Acknowledging the link between $\mu$ and $\rho$ from above, we can therefore conclude that differences in the average level and/or dispersion of effective labor supply are important determinants of the trade structure between two economies if preferences do not have Gorman form. Further insights on the trade structure in the open economy can be obtained by looking at the Grubel-Lloyd index, which is a measure for the share of intra-industry trade and is defined as

$$
G L I=1-\sum_{k} \frac{\left|E X_{k}-I M_{k}\right|}{\sum_{k}\left(E X_{k}+I M_{k}\right)},
$$

where $k \in\{n, \ell\}$ is an industry index. To pin down the extent of trade in necessities, we assume that households in the case of indifference purchase the domestic product. Then, $\rho>1$ establishes $I M_{n}=$ 0 and $E X_{n}=I M_{\ell}-E X_{\ell}$, where the latter follows form the balance of payments condition. As a consequence, we have $\sum_{k}\left(E X_{k}+I M_{k}\right)=2 I M_{\ell}$. In contrast, $\rho<1$ establishes $E X_{n}=0$ and $I M_{n}=E X_{\ell}-I M_{\ell}$, leading to $\sum_{k}\left(E X_{k}+I M_{k}\right)=2 E X_{\ell}$. Substituting into the Grubel-Lloyd index, we obtain

$$
G L I=\left\{\begin{array}{lll}
\frac{E X_{\ell}}{I M_{\ell}}=\frac{1}{\mu} & \text { if } & \rho>1 \\
1 & \text { if } & \rho=1 \\
\frac{I M_{\ell}}{E X_{\ell}}=\mu & \text { if } & \rho<1
\end{array}\right.
$$

The main insights regarding the role of $\rho$ and $t$ for the trade structure in our model are summarized by the following proposition.

Proposition 1 Suppose that trade costs are sufficiently high to support a diversification equilibrium. Then, the country with the higher average level and/or dispersion of effective labor supply has a larger home market for luxuries and is a net-exporter of these goods in the open economy. The share of intraindustry trade, measured by the Grubel-Lloyd index, increases in the similarity of countries in terms of their expenditure shares. If the home market for luxuries differs between the two economies, the share of intra-industry trade increases monotonically in trade cost $t$.

Proof Proposition 1 follows from substituting Eq. (28) into Eqs. (34)-(36) and accounting for the impact of changes in $t$ and $\rho$ on $\mu$ displayed in Figures 1 and 2.

The results in Proposition 1 are closely related to the key finding of Helpman and Krugman (1985) that in a model similar to ours the country with a larger endowment of labor has a larger market for differentiated 
goods and is therefore a net-exporter of these goods in the open economy. Flam and Helpman (1987) and Fajgelbaum et al. (2011) point out that if preferences do not have Gorman form, a larger home market may be the result of a higher average level and/or dispersion of effective labor supply. From our model we can conclude that the link between exogenous differences in the average level and/or dispersion of effective labor supply and the endogenous differences in expenditure shares are more involved if rent sharing between firms and workers makes wages sector-specific. The reason is that a reallocation of workers to the production of luxuries increases per-capita income in the country net-exporting luxuries. This magnifies pre-existing differences in market size from the closed economy. Since the dispersion of labor income is nonmonotonic in the fraction of workers producing luxuries, the reallocation of labor thus described can, however, reduce income dispersion in the open economy, working against the market size stimulus from higher per-capita labor income. Yet, the possible decline in income dispersion cannot dominate, because it is triggered by an increase in the fraction of workers producing luxuries and thus associated with a higher relative mass of local producers (see Figure 1), which further increases the preexisting trade surplus in luxuries.

The trade structure effects in Proposition 1 are well in line with the Linder (1961) hypothesis, which postulates that manufacturing trade is higher between countries featuring more similar per-capita income levels. Whereas the Linder (1961) hypothesis is sometimes used as a rationale for explaining higher levels of overall trade between countries that are more similar in terms of per-capita income (Foellmi et al., 2018), this conclusion is not immediate in a two-sector model. It is well understood from previous work that a higher similarity in per-capita income increases intra-industry trade (see Markusen, 1986; Bergstrand, 1990), but the positive trade stimulus is counteracted by a decline in inter-industry trade (cf. Hunter, 1991). To assess, which of these two effects dominates, we can note from above that total intraplus inter-industry trade is given by $2 E X_{\ell}$ if $\rho \leq 1$ and by $2 I M_{\ell}$ if $\rho>1$. Noting from Figure 1 that $h_{\ell}, M$ decrease while $h_{\ell}^{*}, M^{*}$ increase in $\Lambda^{*}$, it follows from Eqs. (34) and (35) that total intra- plus interindustry trade is lower for $\Lambda^{*}=\Lambda$ (and thus $\rho=1$ ) than for $\Lambda^{*}<\Lambda$ (and thus $\rho<1$ ), contradicting the idea that countries with more similar levels of per-capita income trade more in an open economy (see the Appendix for further details).

To complete the discussion in this section, we finally determine the effects of trade on welfare. For this purpose, we first look at the price index of luxuries. For home, the price index is given by $P_{\ell}=$ $p_{\ell}[M(1+\mu / t)]^{\frac{1}{1-\sigma}}$, where $M(1+\mu / t)$ gives the mass of available luxuries discounted for the price premium paid on imported varieties due to the existence of iceberg trade costs. Using Eqs. (17), (19), (20), and (29), we can express the price index as follows

$$
P_{\ell}=P_{\ell}^{a}\left(\frac{1+t}{t}\right)^{\frac{1}{1-\sigma}}\left[\frac{1-B}{1-B(1+t) /(\mu+t)}\right]^{\frac{1}{1-\sigma}}
$$

where superscript $a$ is used to indicate an autarky variable. If $\alpha=1$, firms producing luxuries do not pay a wage premium. This yields $B=0$ and thus $P_{\ell}=P_{\ell}^{a}(1+1 / t)^{\frac{1}{1-\sigma}}$. In this case, higher trade costs lower the mass of available consumer goods and increase price index $P_{\ell}$, which is to the detriment 
of social welfare. Lacking feedback effects of trade on the level and dispersion of nominal per-capita income, a model variant featuring equal wages in the sector of necessities and luxuries therefore leads to the intuitive result of gains from trade in both economies, irrespective of whether preferences have Gorman form or not. More specifically, for the limiting case of $\alpha=1$ social welfare is given by

$$
V\left(P_{n}, P_{\ell}, \Lambda P_{n}, \psi_{\lambda}\right)=V_{a}\left(P_{n}^{a}, P_{\ell}^{a}, \Lambda P_{n}^{a}, \psi_{\lambda}\right)\left(\frac{1+t}{t}\right)^{\frac{\epsilon}{\sigma-1}},
$$

and thus the same for the two countries and independent of the trade structure in the open economy.

If $\alpha>1$, a reallocation of workers between the two sectors produces an endogenous adjustment in market size captured by $\zeta$ which adds to the home-market effect due to exogenous differences in the average level and/or dispersion of effective labor supply. The now larger home-market effect leads to additional firm entry in the country net-exporting luxuries and to firm exit in the other economy. Since locally produced varieties are not subject to trade costs and since the convexity of the Engel curve implies that the total mass of domestic plus foreign producers of luxuries increases, price index $P_{\ell}$ falls with trade in the country net-exporting this good. This can be seen from Eq. (37), where $\mu<1$ implies $1-B(1+t) /(\mu+t)<1-B$ and thus $P_{\ell}<P_{\ell}^{a}$ in home. The country net-exporting luxuries is unambiguously better off in the open economy, according to Eq. (21), because the fall in the price index of luxuries is accompanied by an increase in nominal income, as more workers are used for the production of luxuries. This nominal income effect is captured by an increase in composite term $\left(\bar{e} / P_{n}\right)^{\varepsilon} \hat{\psi}=$ $\Lambda^{\varepsilon} \hat{\psi}_{\lambda}\left[1+h_{\ell}\left(\alpha^{\varepsilon}-1\right)\right]$.

The effect of a wage premium $\alpha>1$ on the price index in the country net-importing luxuries is a priori not clear. For a given total mass of producers, firm exit at home and firm entry abroad lead to an increase in the price index of luxuries, because imports are subject to trade costs. This effect is counteracted by an increase in the total mass of domestic plus foreign producers, which, all other things equal, lowers the price index of luxuries. In the Appendix, we show that the first effect can dominate for high trade costs if market size differences are sufficiently pronounced. In this case, all domestic workers are worse off in the open economy due to an increase in the price index of luxuries, whereas those workers losing their job in the sector of luxuries and finding a new job in the sector of necessities moreover experience a fall in nominal income. This additional source of welfare loss is captured by a decline in the composite term $\left(\bar{e} / P_{n}\right)^{\varepsilon} \hat{\psi}$ in Eq. (21). We summarize the impact of trade on welfare in the following proposition.

Proposition 2 Suppose that trade costs are sufficiently high to support a diversification equilibrium. Then, if a wage premium does not exist $(\alpha=1)$, there are gains from trade of equal size in both countries and these gains decrease monotonically in trade cost $t$. If $\alpha>1$ causes a wage premium in the sector of luxuries, gains from trade are guaranteed for the country net-exporting luxuries, whereas losses from trade are possible for the country net-importing luxuries.

Proof Analysis in the text and formal proof in the Appendix.

Proposition 2 points to the notable result that in the case of $\alpha=1$ welfare effects of trade are independent 
of the trade structure in the open economy and thus the same for both countries. Thereby, gains from trade are a priori not clear in our setting, because the market outcome in the closed economy is not socially optimal and because we know from the literature of second best that in this case lifting a constraint may aggravate the distortion and lead to welfare loss (see, for instance, Markusen, 1981; Newbery and Stiglitz, 1984, for two prominent contributions in the context of trade). More specifically, our model features increasing external economies to scale in only one sector, and it is well known from studies by Graham (1923), Markusen and Melvin (1981), Ethier (1982), and Francois and Nelson (2002) that in such environments there is a chance that one country loses from trade (even though Grossman and RossiHansberg, 2010, call such outcomes "pathological"). The analysis above reveals that concerns about losses from trade are not justified in our setting if employment in the two sectors promises the same labor return. Since the engine for gains from trade is a decline in the price index of luxuries and since lower trade costs lead to a fall in the price index, gains from trade exist for $\alpha=1$, irrespective of the specific nature of preferences.

For $\alpha>1$, our model features a second source of inefficiency originating from a price distortion in the labor market, which makes wages sector-specific. Adding this distortion, trade can generate losers in the country forfeiting market share in the sector of luxuries, because some workers previously employed in this sector will experience a wage decline. This provides a demand-side explanation for anti-globalization attitudes of workers observed in many industrialized economies over the last decades. However, the insight that the price index of luxuries can increase in response to trade liberalization is even more disconcerting, because it implies that all workers in the country losing market share in the production of luxuries may be worse off with than without trade. If all workers lose, the normative results from our analysis do not depend on the specific choice of a utilitarian welfare function. However, this does not mean that preferences are irrelevant. Since preferences determine how the average level and/or dispersion of effective labor supply influence household expenditures, they affect the trade structure in the open economy and are crucial for the existence of gains and losses from trade. Since the demand-side differences considered here are only relevant for expenditures in a setting with nonhomothetic preferences, the home markets for luxuries do not differ in the limiting case of Cobb-Douglas preferences, making the production structure symmetric and all trade intra-industry. This prevents losses from trade due to an unfavorable reallocation of labor in the open economy.

Giving up the assumption of homothetic preferences may therefore change the rather optimistic view shared by many economists that trade, while not necessarily benefitting all households equally, at least increases economy-wide welfare. Proposition 2 points out that losses from trade are a threat for the poorer country, augmenting pre-existing differences in the well-being of the two economies. This provides a rationale for the view shared by many opponents of globalization that the international distribution of trade surplus is unjust. However, our analysis also reveals that losses from trade are not confined to poorer countries but can extend to countries with a more egalitarian distribution of endowments. This suggests that trade can be a peril for countries in Northern and Central Europe, where the idea of offering equal opportunities plays a particularly important role (cf. Dunnzlaff et al., 2011). Also, the results from our analysis provide a challenge to the idea that redistribution - be it ex ante, through equalization of 
endowments, or ex post, through equalization of outcome - can be a successful instrument to increase support for trade liberalization (cf. Davidson and Matusz, 2006; Egger and Fischer, 2018). Even if the trade reform generates aggregate gains, policy intervention that aims at distributing theses gains more equally will influence the trade structure with unintended welfare consequences. However, such insights should not be misunderstood as an argument against free trade. Losses from trade are the result of preexisting price distortions in the product and labor market and not per se a consequence of falling trade costs. Our analysis points out that abolishing such distortions may be a more important measure to achieve support for a trade reform than the compensation of losers.

\section{Extensions}

In this section, we consider two extensions of our benchmark model. In the first one, we allow for positive assortative matching, implying that workers with higher effective labor supply end up in the sector of luxuries. Assuming that firms must invest into a screening technology to gather (imperfect) information upon the type of applicants, the thus modified setting produces endogenous fixed and variable production costs, thereby opening an additional adjustment margin to a fall in trade costs. In the second extension, we consider differences of the two economies in the wage premium paid by luxury producers and analyze to what extent the predictions of our model change if we consider supply-side reasons for comparative advantage instead of demand-side reasons for the home-market effect as a motive for inter-industry trade.

\subsection{Screening and assortative matching}

In the analysis above, firms in the luxury sector are indifferent between hiring workers with high or low effective labor supply, because the same workplace capacity is needed for each employed unit of labor input. Whereas this assumption facilitates the analysis, it differs from the usual approach which associates employment with installment of a workplace at a cost that is independent of the worker's effective labor supply. With this alternative specification, firms producing luxuries prefer employing workers with higher effective labor supply. However, following Helpman et al. $(2010,2017)$ we assume that firms cannot freely observe the effective labor supply of workers prior to their employment and therefore have to screen the pool of applicants to gather information upon their $\lambda$-level. Screening is costly and provides an imperfect signal about the effective labor supply of applicants. More specifically, firms detect whether applicants are above or below a threshold, $\lambda_{u}$, and the costs of screening, $P_{n} F\left(\lambda_{u}\right)$, increase in this threshold with constant elasticity $\varphi>0: F\left(\lambda_{u}\right)=\lambda_{u}^{\varphi}$. Installing a workplace has costs $P_{n}$ and if the

average worker provides labor input $\Lambda_{u} \equiv\left[1-L\left(\lambda_{u}\right)\right]^{-1} \int_{\lambda_{u}}^{\bar{\lambda}} \lambda d L(\lambda), q_{\ell} / \Lambda_{u}$ workplaces are needed to employ $q_{\ell}$ units of labor input. Profits of the firm then correspond to $\Pi=\pi-P_{n} q_{\ell} \Lambda_{u}^{-1}-P_{n} F\left(\lambda_{u}\right)-P_{n} f$.

Adopting from Helpman et al. (2010) the assumption that effective labor supply is Pareto distributed, with $\underline{\lambda}>0, \bar{\lambda} \rightarrow \infty$, and $L(\lambda)=1-(\lambda / \underline{\lambda})^{-g}, g>1$, we have $\Lambda_{u}=\frac{g}{g-1} \lambda_{u}$, and the first-order 
conditions for the optimal choice of $q_{\ell}$ and $\lambda_{u}$ are given by

$$
\frac{\partial \Pi}{\partial q_{\ell}}=\frac{\sigma-1}{\sigma} \frac{\kappa r}{q_{\ell}}-\frac{P_{n}}{\Lambda_{u}}=0, \quad \frac{\partial \Pi}{\partial \lambda_{u}}=\frac{P_{n} q_{\ell}}{\Lambda_{u}} \frac{1}{\lambda_{u}}-\varphi P_{n} \frac{F\left(\lambda_{u}\right)}{\lambda_{u}}=0 .
$$

As formally shown in the Appendix, under the sufficient condition of $\varphi>\sigma-1$, the Hesse matrix of the maximization problem (evaluated at the solutions for the first-order conditions) is negative semidefinite. This implies that if an interior solution exists, it must be a maximum. Furthermore, combining the firstorder conditions in $\left(13^{\prime}\right)$ with the zero-profit condition $\Pi=0$, we can solve for

$$
\lambda_{u}=\left(\frac{f(\sigma-1)}{\varphi-\sigma+1}\right)^{\frac{1}{\varphi}} \equiv \hat{\lambda}_{u}, \quad \Lambda_{u}=\frac{g}{g-1}\left(\frac{f(\sigma-1)}{\varphi-\sigma+1}\right)^{\frac{1}{\varphi}} \equiv \hat{\Lambda}_{u} .
$$

A solution with a positive level of screening, $\hat{\lambda}_{u}>\underline{\lambda}$, requires $f(\sigma-1) /(\varphi-\sigma+1)>\underline{\lambda}^{\varphi}$. Accounting for the bargaining solution in Eq. (12), we can summarize the outcome of the firm's maximization problem as follows

$$
w_{\ell}=\frac{\alpha}{\hat{\Lambda}_{u}} P_{n}, \quad \Pi=\frac{\kappa r}{\Phi}-P_{n} f
$$

with $\Phi \equiv \sigma \varphi /(\varphi-\sigma+1)>\sigma$. Thereby, $\hat{\alpha} \equiv \alpha / \hat{\Lambda}_{u}>1$ is needed to ensure that firms producing luxuries pay a wage premium and therefore make a job application attractive for workers.

To solve for the general equilibrium outcome, we can proceed as in the benchmark model and determine the mass of firms and the fraction of workers producing luxuries, $M$ and $h_{\ell}$, respectively. Acknowledging that $q_{\ell} / \hat{\Lambda}_{u}$ gives the number of workers per firm, we can derive a first relationship between $h_{\ell}$ and $M$ from the first-order condition in Eq. $\left(13^{\prime}\right)$ as follows (see the Appendix):

$$
h_{\ell} H w=\frac{\sigma-1}{\sigma} \kappa M r
$$

Eq. $\left(17^{\prime}\right)$ reflects constant markup pricing and shows once again that firms pay a constant fraction of their revenues as a wage bill to their workforce. Because in the modified setting considered here firms pay the same workplace installment costs for each worker and because in total these installment costs are equal to their wage payments, the wage bill received in the sector of luxuries is independent of the now higher effective labor supply of the workforce. Of course, the share of workers employed in the sector of luxuries, $h_{\ell}$, cannot be larger than the share of workers with an effective labor supply above the threshold $\hat{\lambda}_{u},\left(\hat{\lambda}_{u} / \underline{\lambda}\right)^{-g}$. To avoid a corner solution, we discuss below a necessary parameter constraint and assume for now excess supply of workers with effective labor endowment $\lambda>\hat{\lambda}_{u}$. This implies that the share of workers with effective labor supply above the threshold $\hat{\lambda}_{u}$ finding employment in the sector of luxuries is smaller than one: $\gamma_{h} \equiv h_{\ell}\left(\hat{\lambda}_{u} / \underline{\lambda}\right)^{g}<1$.

To determine a second relationship between $h_{\ell}$ and $M$, we employ goods market clearing in the sector 
of luxuries, $P_{\ell} X_{\ell}=M r$, which is derived in the Appendix and given by

$$
H \Lambda w\left[1-\beta \Lambda^{-\varepsilon} \psi_{\lambda}\right]+h_{\ell} H w \frac{\sigma}{\sigma-1} \frac{1}{\kappa} \hat{B}=M r
$$

with $\hat{B} \equiv \frac{\sigma-1}{\sigma} \kappa \hat{\Lambda}_{u}\left[(\hat{\alpha}-1)-\left(\hat{\alpha}^{1-\varepsilon}-1\right) \beta \hat{\Lambda}_{u}^{-\varepsilon} \psi_{\lambda}\right]$ and $\Lambda=\frac{g}{g-1} \underline{\lambda}, \psi_{\lambda}=\left(\frac{g}{g-1}\right)^{\varepsilon} \frac{g-1}{g+\varepsilon-1}$ due to our assumption that the distribution of effective labor supply is Pareto. Combining Eqs. $\left(17^{\prime}\right)$ and $\left(18^{\prime}\right)$ and making use of zero-profit condition $\kappa r=\Phi P_{n} f$, we can derive explicit solutions for $M$ and $h_{\ell}$ :

$$
M=\frac{\kappa}{1-\hat{B}} \frac{H \Lambda\left[1-\beta \Lambda^{-\varepsilon} \psi_{\lambda}\right]}{\Phi f}, \quad h_{\ell}=\frac{\sigma-1}{\sigma} \frac{\kappa}{1-\hat{B}} \Lambda\left[1-\beta \Lambda^{-\varepsilon} \psi_{\lambda}\right] .
$$

A higher average effective labor supply increases demand for luxuries through two channels. On the one hand, there is a common income effect that increases expenditures for both goods. On the other hand, there is a further demand stimulus for luxuries, which is specific to nonhomothetic preferences, because the now richer households devote a larger fraction of expenditures to the consumption of luxuries. Both of these effects also exist in the benchmark model. However, there, the common income effect was neutralized by an increase in the costs of employing the additional amount of labor needed to fulfill the increased demand for luxuries. This is different in the model variant considered here. Because workplace installment costs per worker are not affected by a common increase in effective labor supply, the common income effect is not neutralized. From Eq. $\left(19^{\prime}\right)$, we can moreover infer that an interior solution with $\gamma_{h}=h_{\ell}\left(\hat{\lambda}_{u} / \underline{\lambda}\right)^{g}<1$ requires

$$
\kappa \frac{\sigma-1}{\sigma} \Lambda\left[1-\beta \Lambda^{-\varepsilon} \psi_{\lambda}\right]<(1-\hat{B})\left[\left(\frac{f(\sigma-1)}{\varphi-\sigma+1}\right)^{\frac{1}{\varphi}} \frac{1}{\underline{\lambda}}\right]^{-g} .
$$

Despite the complications arising from endogenous fixed costs and despite the additional parameter constraint needed to achieve an interior equilibrium, the main insights from the benchmark model remain intact. Since the results for the open economy can be derived for the more sophisticated model variant considered here by following the derivation steps from the main text, we do not repeat the analysis and leave the formal details to the interested reader.

\subsection{Supply-side differences due to country-specific wage premia}

We now consider the role of supply-side differences of the two countries and assume that a wage premium is paid by luxury producers only in the foreign economy. Accordingly, we set $\alpha^{*}>\alpha=1$, while we make countries symmetric in all other respects, including the average level and dispersion of effective labor supply. Similar to the benchmark model, we can apply the zero-profit conditions for home and foreign to link differences in the price indices for luxuries to market size differences. As formally shown 
in the Appendix, this gives

$$
\rho \zeta=\frac{t \xi^{\sigma}-1}{t-\xi^{\sigma}}\left(\frac{P_{\ell}}{P_{\ell}^{*}}\right)^{\sigma-1}
$$

where $\rho, \zeta$ are defined as above, and $\rho=1$ holds, because the two countries do not differ in the average level and dispersion of effective labor supply, while $\zeta>1$ follows, because only the foreign market offers a wage premium for workers employed in the production of luxuries. On the one hand, this indicates that the local market for luxuries is larger in the country featuring a price distortion in the labor market, which is foreign in our case. On the other hand, this country has a comparative disadvantage in producing luxuries, which is reflected by $\xi \equiv \frac{p_{\ell}^{*}}{p_{\ell}}=\frac{\kappa}{\kappa^{*}}=\frac{\sigma+(\sigma-1) \alpha^{*}}{2 \sigma-1}>1$. From Eq. (23') we see that $t>\xi^{\sigma}$ is a necessary (not sufficient) condition for some production of luxuries to remain in the foreign economy. With this result at hand, we can determine the share of revenues achieved in the domestic market $(d)$ and the export market $(x)$. This gives for home and foreign

$$
\frac{r_{d}}{r}=t \frac{t-\xi^{\sigma}}{t^{2}-1}, \quad \frac{r_{x}}{r}=\frac{t \xi^{\sigma}-1}{t^{2}-1} \quad \text { and } \quad \frac{r_{d}^{*}}{r^{*}}=t \frac{t-\xi^{-\sigma}}{t^{2}-1}, \quad \frac{r_{x}^{*}}{r^{*}}=\frac{t \xi^{-\sigma}-1}{t^{2}-1}
$$

respectively. An increase in the wage premium in the foreign country increases $\xi$ and thus the comparative advantage of home in the production of luxuries. However, it also increases the market for luxuries in foreign and induces firms from both countries to increase their revenues there. As a consequence, a higher $\xi$ lowers $r_{d} / r$ and increases $r_{x} / r$, with the effect mirrored in the foreign country by a decrease in $r_{x}^{*} / r^{*}$ and an increase in $r_{d}^{*} / r^{*}$.

The assumption of asymmetric production costs does not affect constant markup pricing and the induced result that the wage bill paid by luxury producers is a constant fraction of their revenues. This establishes a positive link between the fraction of workers and the number of firms producing luxuries that is well understood from Eqs. (17) and (25). However, asymmetric production costs change the market clearing conditions for luxuries in the open economy to

$$
\begin{aligned}
H \Lambda w\left[1-\beta \Lambda^{-\varepsilon} \psi_{\lambda}\right] & =M r t \frac{t-\xi^{\sigma}}{t^{2}-1}+M^{*} r^{*} \frac{t \xi^{-\sigma}-1}{t^{2}-1}, \\
H \Lambda w\left[1-\beta \Lambda^{-\varepsilon} \psi_{\lambda}\right]+h_{\ell}^{*} H \Lambda w \frac{\sigma}{\sigma-1} \frac{1}{\kappa^{*}} B^{*} & =M^{*} r^{*} t \frac{t-\xi^{-\sigma}}{t^{2}-1}+M r \frac{t \xi^{\sigma}-1}{t^{2}-1} .
\end{aligned}
$$

Combining markup pricing with the two market clearing conditions, we can solve for firm ratio $\mu=$ $M^{*} / M$, according to

$$
\mu=\frac{1}{\xi} \frac{t^{2}-2 t \xi^{\sigma}+1}{t^{2}-2 t \xi^{-\sigma}+1-\left(t^{2}-1\right) B^{*}}
$$

with

$$
\frac{d \mu}{d t}=\frac{2\left[t\left(1-B^{*}\right)-\xi^{-\sigma}\right]}{t^{2}-2 t \xi^{-\sigma}+1-\left(t^{2}-1\right) B^{*}}\left[\frac{1}{\xi} \frac{t-\xi^{\sigma}}{t\left(1-B^{*}\right)-\xi^{-\sigma}}-\mu\right] .
$$


In the Appendix, we show that $d \mu / d t>0$, while $\lim _{t \rightarrow \infty} \mu=\frac{2 \sigma-1}{2 \sigma-1+(\sigma-1)\left[\left(\alpha^{*}\right)^{1-\varepsilon}-1\right] \beta \Lambda^{-\varepsilon} \psi_{\lambda}}<1$. This implies that $\mu<1$ extends to all possible trade costs and that the country with a comparative disadvantage in the production of luxuries hosts fewer luxury goods producers in the open economy. Furthermore, from Eq. $\left(28^{\prime}\right)$, we see that a positive production level of luxuries in foreign is given by $t>\xi^{\sigma}+$ $\sqrt{\xi^{2 \sigma}-1}$, whereas the parameter domain supporting a positive production level of necessities in home can be determined by combining Eq. $\left(28^{\prime}\right)$ with Eqs. (17), $\left(26^{\prime}\right)$, and zero-profit condition $\kappa r=\sigma P_{n} f$, and it is given by

$$
\kappa \frac{\sigma-1}{\sigma}\left[1-\beta \Lambda^{-\varepsilon} \psi_{\lambda}\right]<\frac{t+\mu \xi^{1-\sigma}}{t+1} \frac{t-\xi^{\sigma}}{t-1}
$$

Similar to the benchmark model the foreign to domestic firm ratio $\mu$ is decisive for the trade structure in the open economy. Making use of the zero-profit condition, we can compute home's total value of exports and imports of luxuries according to

$$
\begin{aligned}
& E X_{\ell}=M r_{x}=M \frac{t \xi^{\sigma}-1}{t^{2}-1} \frac{\sigma P_{n} f}{\kappa} \\
& I M_{\ell}=M^{*} r_{x}^{*}=M \mu \frac{t \xi^{-\sigma}-1}{t^{2}-1} \frac{\sigma P_{n} f}{\kappa^{*}}
\end{aligned}
$$

respectively. Combining Eqs. $\left(34^{\prime}\right)$ and (35') then implies $I M_{\ell}=\mu \xi^{1-\sigma} \frac{t-\xi^{\sigma}}{t \xi^{\sigma}-1} E X_{\ell}$, and, acknowledging $G L I=\mu \xi^{1-\sigma} \frac{t-\xi^{\sigma}}{t \xi^{\sigma}-1}<1$, we can therefore safely conclude that home exports luxuries, because it has a comparative advantage in producing these goods, which dominates the home-market effect in our setting. The share of intra-industry-trade increases in trade cost parameter $t$ and it decreases in foreign's wage premium $\alpha^{*}$, whereas total (intra- plus inter-industry) trade increases in $\alpha^{*}$ and decreases in $t$. These effects are well understood from the benchmark model.

We complete the discussion in this section with a brief look at the welfare effects of trade. In home, luxury producers do not pay a wage premium, and hence changes in the allocation of workers do not affect the level and dispersion of nominal income. This implies that all welfare effects of trade are due to changes in the price index of luxuries, which can be expressed as $P_{\ell}=p_{\ell}\left[M \frac{t+\mu \xi^{1-\sigma}}{t}\right]^{\frac{1}{1-\sigma}}$. Making use of market clearing condition (26'), zero-profit condition $\kappa r=\sigma P_{n} f$, and the solution for firm ratio $\mu$ in Eq. $\left(28^{\prime}\right)$, we can compute $d P_{\ell} / d t>0$. This implies that home benefits from trade, because it specializes according to the law of comparative advantage in those goods, whose production features increasing external economies to scale and whose exchange is subject to trade costs. In foreign, things are less clear, because there are two potentially counteracting effects. There are adjustments in the share of workers producing luxuries, which affect welfare through changes in nominal income due to the wage premium paid in the sector of luxuries. At already high trade costs, a further increase in $t$ increases the fraction of workers producing luxuries in foreign, with positive effects on nominal income and welfare. This effect is supplemented by a change in the price index of luxuries, which in the foreign economy is given by $P_{\ell}^{*}=p_{\ell}^{*}\left[M^{*} \frac{1+t \mu \xi^{1-\sigma}}{t \mu \xi^{1-\sigma}}\right]^{\frac{1}{1-\sigma}}$. Whereas general effects of trade on price index $P_{\ell}^{*}$ are difficult to determine, we show in the Appendix that at an initially high level of $t$, the price index increases in trade 
costs if the price distortion in the labor market is small ( $\xi$ close to one), whereas the opposite is true if the price distortion is large ( $\xi$ close to infinity). This indicates that the country losing market share of those goods, whose production features increasing external economies to scale, can be worse off in the open than in the closed economy if supply-side differences are sufficiently pronounced, whereas gains from trade are guaranteed for both trading partners if supply-side differences are small. This conclusion holds for arbitrary levels of $\varepsilon$, and hence does not depend on the specific nature of preferences.

\section{Conclusion}

We have developed a two-country model, in which ex ante differences in the average level and dispersion of effective labor supply are important exogenous sources of demand-side asymmetries, because households have nonhomothetic preferences. The assumption of nonhomothetic preferences produces non-linear Engel curves and makes in a textbook model of the home-market effect, with two output sectors and labor as the only factor input, the differentiated good a luxury and the outside good a necessity. Assuming that production of luxuries promises a wage premium due to firm-level rent sharing and assuming that the export of luxuries is subject to trade costs, we show that the country featuring a higher average level and/or dispersion of effective labor supply has a larger home market and therefore becomes net-exporter of luxuries in the open economy. Due to a price distortion in the labor market, the trade pattern is an important factor of welfare in the open economy. The country that increases its market share and net-exports luxuries benefits, whereas the country that lowers its market share and net-imports luxuries can lose from trade. This implies that trade can increase pre-existing welfare differences and hurt countries with a lower average level and/or lower dispersion of effective labor supply.

In an extension of our model, we consider screening and assortative matching of workers featuring high effective labor supply with firms producing luxuries. This modified framework generates endogenous fixed and variable costs of production and therefore accounts for an additional adjustment margin through which trade can affect welfare in an open economy. Whereas the additional adjustment margin makes the analysis more complicated, the main insights from the benchmark model regarding the link of trade pattern and welfare remain intact. In a second extension, we consider asymmetries of countries in the wage premia paid by luxury goods producers. This modification generates a supply-side asymmetry and sheds light on the role of comparative advantage for trade structure and welfare in the open economy. Accordingly, the country featuring the stronger price distortion in the labor market becomes net-importer of luxuries and, depending on the strength of the distortion, can win or lose from trade, irrespective of the specific nature of preferences. This suggests that the choice of preferences is particularly relevant when demand-side differences are key for the trade pattern in the open economy, whereas the choice of preferences seems less important if supply-side asymmetries are decisive.

This paper provides a first step to introduce PIGL preferences into models of international trade. Relying on these preferences, we have shown that problems associated with the aggregation of heterogeneous households can be avoided and new insights on how demand-side factors affect trade and welfare can be gained even if one chooses to leave the Gorman class. In the specific application considered here, 
we have shed light on the interaction between supply-side distortions and demand-side asymmetries for the relationship of trade and welfare in open economies. Thereby, we have left other interesting topics aside. For instance, we have not considered unemployment and thus have excluded one important variable, whose adjustment to trade has been subject to a controversial debate over the last few decades. Furthermore, while briefly discussing limitations to redistributing the gains from trade under nonhomothetic preferences, we have not addressed in detail the costs and benefits of tax-transfer systems in open economies. Whereas extending our model in both directions is a worthwhile task for future research, doing so is clearly beyond the scope of this paper.

\section{References}

Abowd, J. M. ., F. Kramarz, P. Lengermann, K. L. McKinney, and S. Roux (2012): "Persistent Inter-Industry Wage Differences: Rent Sharing and Opportunity Costs," IZA Journal of Labor Economics, 1, 1-25.

AlmÅs, I., T. K. Beatty, And T. F. Crossley (2018): "Lost in Translation: What do Engel Curves Tell us about the Cost of Living?" CESifo Working Paper No. 6886.

Amiti, M. And D. R. DAVIS (2012): “Trade, Firms, and Wages: Theory and Evidence," Review of Economic Studies, 79, 1-36.

AtKinson, A. B. (1970): "On the Measurement of Inequality," Journal of Economic Theory, 2, 244 263.

Autor, D. H., D. Dorn, And G. H. HAnson (2013): "The China Syndrome: Local Labor Market Effects of Import Competition in the United States," American Economic Review, 103, 2121-2168.

Bastos, P. And U. Kreickemeier (2009): "Unions, Competition and International Trade in General Equilibrium," Journal of International Economics, 79, 238-247.

Benassy, J.-P. (1996): "Taste for Variety and Optimum Production Patterns in Monopolistic Competition," Economics Letters, 52, 41-47.

Bergstrand, J. H. (1989): “The Generalized Gravity Equation, Monopolistic Competition, and the Factor-Proportions Theory in International Trade," Review of Economics and Statistics, 71, 143-153.

(1990): "The Heckscher-Ohlin-Samuelson Model, the Linder Hypothesis and the Determinants of Bilateral Intra-Industry Trade," Economic Journal, 100, 1216-1229.

BERnASCONI, C. (2013): "Similarity of Income Distributions and the Extensive and Intensive Margin of Bilateral Trade Flows," University of Zurich, Department of Economics Working Paper No. 115.

Bertoletti, P. AND F. Etro (2017): "Monopolisitic Competition when Income Matters," Economic Journal, 127, 1217-1243.

(2018): “Monopolistic Competition with GAS Preferences," DISEI Working Paper No. 165.

Blanchflower, D. G., A. J. Oswald, And P. Sanfey (1996): "Wages, Profits, and Rent-Sharing," Quarterly Journal of Economics, 111, 227-251. 
BOPPART, T. (2014): "Structural Change and the Kaldor Facts in a Growth Model with Relative Price Effects and Non-Gorman Preferences," Econometrica, 82, 2167-2196.

BRECHER, R. A. (1974): “Minimum Wage Rates and the Pure Theory of International Trade," Quarterly Journal of Economics, 88, 98-116.

Bruegemann, B., P. Gautier, And G. Menzio (2018): "Intra Firm Bargaining and Shapley Values," Review of Economic Studies, forhcoming.

Caron, J., T. FAlly, And J. R. Markusen (2014): "International Trade Puzzles: A Solution Linking Production and Preferences," Quarterly Journal of Economics, 129, 1501-1552.

Dalgin, M., V. Trindade, And D. Mitra (2008): "Inequality, Nonhomothetic Preferences, and Trade: A Gravity Approach,” Southern Economic Journal, 74, 747-774.

DAlton, H. (1920): “The Measurement of the Inequality of Incomes,” Economic Journal, 30, 348-361.

DAuth, W., S. Findeisen, AND J. SÜDEKUM (2014): "The Rise of the East and the Far East: German Labor Markets and Trade Integration,” Journal of the European Economic Association, 12, 1643-1675.

DAVIDSON, C. AND S. J. MAtusz (2006): “Trade Liberalization and Compensation," International Economic Review, 47, 723-747.

Davidson, C., S. J. Matusz, And A. Shevchenko (2008): "Outsourcing Peter to Pay Paul: HighSkill Expectations and Low-Skill Wages with Imperfect Labor Markets," Macroeconomic Dynamics, $12,463-479$.

DAVIS, D. R. (1998): “The Home Market, Trade, and Industrial Structure,” American Economic Review, $88,1264-1276$.

Deaton, A. And J. Muellbauer (1980): “An Almost Ideal Demand System,” American Economic Review, 70, 312-326.

Dhingra, S. AND J. MORRow (2016): "Monopolistic Competition and Optimum Product Diversity under Firm Heterogeneity," Journal of Political Economy, forthcoming.

Dickens, W. T. AND L. F. KATZ (1987): "Inter-Industry Wage Differences and Industry Characteristics," in Unemployment and the Structure of Labor Markets, ed. by K. Lang and J. S. Leonard, Basil Blackwell, New York.

Dornbusch, R., S. Fischer, And P. SAmuelson (1977): "Comparative Advantage, Trade, and Payments in a Ricardian Model with a Continuum of Goods," American Economic Review, 67, 823839.

Dunnzlaff, L., D. Neumann, J. Niehaus, And A. Peichl (2011): "Equality of Opportunity and Redistribution in Europe," in Inequality of Opportunity: theory and Measurement, ed. by J. G. Rodriguez, Emerald Groupp Publishin Limited, vol. 19 of Research on Economic Inequality, chap. 5, 99-129.

Eaton, J. And S. Kortum (2002): “Technology, Geography, and Trade,” Econometrica, 70, 17411779. 
EgGer, H. AND C. FISChER (2018): "Increasing resistance to Globalization: The Role of Trade in Tasks,” DICE Discussion Paper No. 305.

Egger, H. And U. Kreickemeier (2009): "Firm Heterogeneity and The Labor Market Effects of Trade Liberalization,” International Economic Review, 50, 187-216.

_ (2012): “Fairness, Trade, and Inequality," Journal of International Economics, 86, 184-196.

EthiER, W. J. (1982): "Decreasing Costs in International Trade and Frank Graham's Argument for Protection," Econometrica, 50, 1243-1268.

Fajgelbaum, P., G. M. Grossman, And E. Helpman (2011): "Income Distribution, Product Quality, and International Trade," Journal of Political Economy, 119, 721-765.

FALly, T. (2018): “Integrability and Generalized Separability,” Tech. rep., UC Berkley, Unpublised Manuscript.

Feenstra, R. C. And M. B. Reinsdorf (2000): "An Exact Price Index for the Almost Ideal Demand System," Economics Letters, 66, 159-162.

Felbermayr, G., J. Prat, And H.-J. Schmerer (2011): "Globalization and Labor Market Outcomes: Wage Bargaining, Search Frictions, and Firm Heterogeneity." Journal of Economic Theory, $146,39-73$.

FIELER, A. C. (2011): "Nonhomotheticity and Bilateral Trade: Evidence and a Quantitative Explanation," Econometrica, 79, 1069-1101.

Flam, H. And E. Helpman (1987): "Vertical Product Differentiation and North-South Trade," American Economic Review, 77, 810-820.

Foellmi, R., C. HePenstrick, AND J. ZweimÜller (2018): "International Arbitrage and the Extensive Margin of Trade between Rich and Poor Countries," Review of Economic Studies, 85, 475-510.

Francois, J. F. AND S. KAPlan (1996): "Aggregate Demand Shifts, Income Distribution, and the Linder Hypothesis," Review of Economics and Statistics, 78, 244-250.

Francois, J. F. AND D. Nelson (2002): “A Geometry of Specialisation,” Economic Journal, 112, 649-678.

Graham, F. D. (1923): "Some Aspects of Protection Further Considered," Quarterly Journal of Economics, 37, 199-227.

Grossman, G. M. And E. Rossi-Hansberg (2010): "External Economies and International Trade Redux," Quarterly Journal of Economics, 125, 829-858.

Hallak, J. C. (2010): "A Product-Quality View of the Linder Hypothesis," Review of Economics and Statistics, 92, 453-466.

Hamilton, B. W. (2001): "Using Engel's Law to Estimate CPI Bias," American Economic Review, 91, 619-630.

Helpman, E. AND O. ItSKhoKi (2010): "Labour Market Rigidities, Trade and Unemployment," Review of Economic Studies, 77, 1100-1137. 
Helpman, E., O. Itskhoki, M.-A. Muendler, And S. J. Redding (2017): "Trade and Inequality: From Theory to Estimation," The Review of Economic Studies, 84, 357.

Helpman, E., O. Itskhoki, And S. Redding (2010): "Inequality and Unemployment in a Global Economy," Econometrica, 78, 1239-1283.

Helpman, E. And P. R. KRugman (1985): Market structure and Foreign Trade, MIT Press, Cambridge/MA.

Hunter, L. (1991): “The Contribution of Non-Homothetic Preferences to Trade," Journal of International Economics, 30, 345-358.

KatZ, L. F. AND D. Autor (1999): "Changes in the Wage Structure and Earnings Inequality," in Handbook of Labor Economics, ed. by O. Ashenfelter and D. Card, Elsevier Science, North-Holland, vol. 3A, chap. 26, 1463-1555.

Krueger, A. B. And L. H. Summers (1988): "Efficiency Wages and the Inter-industry Wage Structure," Econometrica, 56, 259-293.

Krugman, P. (1980): "Scale Economies, Product Differentiation, and the Pattern of Trade." American Economic Review, 70, 950 - 959.

Krugman, P. R. (1979): "Increasing Returns, Monopolistic Competition, and International Trade," Journal of International Economics, 9, 469-479.

Linder, S. B. (1961): An Essay on Trade and Transformation, Almquist \& Wicksell.

Markusen, J. R. (1981): "Trade and the Gains from Trade with Imperfect Competition," Journal of International Economics, 11, 531-551.

(1986): "Explaining the Volume of Trade: An Eclectic Approach," American Economic Review, $76,1002-1011$.

(2013): "Expansion of Trade at the Extensive Margin: A General Gains-from-Trade Result and Illustrative Examples," Journal of International Economics, 89, 262-270.

Markusen, J. R. And J. R. Melvin (1981): "Trade, Factor Prices, and the Gains from Trade with Increasing Returns to Scale," Canadian Journal of Economics, 14, 450-469.

Matsuyama, K. (2000): "A Ricardian Model with a Continuum of Goods under Non-homothetic Preferences: Demand Complementarities, Income Distribution, and North-South Trade," Journal of Political Economy, 108, 1093-1120.

_ (2015): "The Home Market effect and Patterns of Trade between Rich and Poor Countries," CFM Discussion Paper No. 1519.

(2018): "Engel's Law in the Global Economy: Demand-Induced Patterns of Structural Change, Innovation, and Trade," Econometrica, forthcoming.

MCFAdDEn, D. (1978): "Modelling the Choice of Residential Location," in Spatial Interaction Theory and Planning Models, ed. by A. Karlqvist, L. Lundqvist, F. Snickars, and W. J. W., Elsevier Science, North-Holland. 
Melitz, M. J. (2003): "The Impact of Trade on Intra-Industry Reallocations and Aggregate Industry Productivity," Econometrica, 71, 1695-1725.

Muellbauer, J. (1975): “Aggregation, Income Distribution and Consumer Demand," Review of Economic Studies, 42, 525-543.

(1976): “Community Preferences and the Representative consumer," Econometrica, 44, 979-999.

Myrdal, G. (1957): Economic Theory and Under-Developed Regions, Gerald Duckworth \& Co.

NeARy, J. ANd M. MrázovÁ (2017): "Not so Demanding: Demand Structure and Firm Behavior," American Economic Review, 107, 3835-3874.

NeAry, P. J., M. MrázovÁ, And M. Parenti (2017): "Sales and Markup dispersion: Theory and Empirics," Unpublished Manuscript, University of Oxford.

Newbery, D. M. G. And J. E. Stiglitz (1984): "Pareto Inferior Trade," Review of Economic Studies, $51,1-12$.

PARFIT, D. (1997): “Equality and Priority,” Ratio, 10, 202-221.

PollaK, R. A. (1972): “Generalized Separability,” Econometrica, 40, 431-453.

Pollak, R. A. And T. J. Wales (1992): Demand System Specification and Estimation, Oxford University Press.

SimonovskA, I. (2015): "Income differences and Prices of Tradables," Review of Economic Studies, 82, $1612-1656$.

Stockey, N. L. (1991): "The Volume and Composition of Trade Between Rich and Poor Countries," Review of Economic Studies, 58, 63-80.

Stole, L. A. And J. Zwiebel (1996): "Intra-Firm Bargaining under Non-Binding Contracts," The Review of Economic Studies, 63, 375-410.

Thursby, J. G. And M. C. Thursby (1987): "Bilateral Trade Flows, the Linder Hypothesis, and Exchange Risk," Review of Economics and Statistics, 69, 488-495.

Vollmer, S. And I. Martínez-Zarzoso (2016): "Bilateral Trade Flows and Income Distribution Similarity," PLoS one, 11, 1-12.

\section{A Appendix}

\section{A.1 A closed form representation of the direct utility function}

Applying Roy's identity to Eq. (2) gives the Marshallian demand functions in Eq. (3). These demand functions can be used to solve for

$$
\frac{P_{n}}{P_{\ell}}=\frac{X_{\ell}^{i}}{\left(\frac{X_{n}^{i}}{\beta}\right)^{\frac{1}{1-\varepsilon}}-X_{n}^{i}} \quad \text { and } \quad \frac{e^{i}}{P_{\ell}}=\frac{P_{n}}{P_{\ell}}\left(\frac{X_{n}^{i}}{\beta}\right)^{\frac{1}{1-\varepsilon}} .
$$


Substitution into Eq. (2), then gives the direct utility function

$$
u\left(X_{n}^{i}, X_{\ell}^{i}\right)=\frac{1}{\varepsilon}\left(X_{\ell}^{i}\right)^{\varepsilon} \frac{\left(\frac{X_{n}^{i}}{\beta}\right)^{\frac{\varepsilon}{1-\varepsilon}}-\beta}{\left[\left(\frac{X_{n}^{i}}{\beta}\right)^{\frac{1}{1-\varepsilon}}-X_{n}^{i}\right]^{\varepsilon}},
$$

which is well defined only if the consumption level of luxuries is strictly positive and it has a value of zero for all levels of purchased necessities if $X_{\ell}^{i}=0$. This completes the proof.

\section{A.2 Derivation of price index $P_{\ell}$}

Acknowledging Eq. (4), households choose $X_{n}^{i}, x_{\ell}^{i}(\omega)$ to maximize utility Eq. (A.2), subject to their budget constraint $P_{n} X_{n}^{i}+\int_{\omega \in \Omega} p_{\ell}(\omega) x_{\ell}^{i}(\omega) \leq e^{i}$. The first-order conditions for the respective Lagrangian problem yield

$$
\frac{x_{\ell}^{i}(\omega)^{-\frac{1}{\sigma}}}{\left(X_{\ell}^{i}\right)^{\frac{\sigma-1}{\sigma}}}\left[\left(\frac{X_{n}^{i}}{\beta}\right)^{\frac{1}{1-\varepsilon}}-X_{n}^{i}\right]=\frac{p_{\ell}(\omega)}{P_{n}}
$$

This establishes for any two varieties of luxuries $\omega$ and $\hat{\omega}$ a link of their consumption expenditures according to $p_{\ell}(\omega) x_{\ell}^{i}(\omega)=x_{\ell}^{i}(\hat{\omega}) p_{\ell}(\hat{\omega})\left[\frac{p_{\ell}(\omega)}{p_{\ell}(\hat{\omega})}\right]^{1-\sigma}$. Integrating over $\omega$, then gives

$$
\int_{\omega \in \Omega} p_{\ell}(\omega) x_{\ell}^{i}(\omega) d \omega=x_{\ell}^{i}(\hat{\omega}) p_{\ell}(\hat{\omega})^{\sigma} \int_{\omega \in \Omega} p_{\ell}(\omega)^{1-\sigma} d \omega
$$

Using the latter together with $X_{n}^{i}=\beta\left(\frac{e^{i}}{P_{n}}\right)^{1-\varepsilon}$ from Eq. (3) in the binding budget constraint, we obtain

$$
e^{i}\left[1-\beta\left(\frac{e^{i}}{P_{n}}\right)^{-\varepsilon}\right]=x_{\ell}^{i}(\hat{\omega}) p_{\ell}(\hat{\omega})^{\sigma} \int_{\omega \in \Omega} p_{\ell}(\omega)^{1-\sigma} d \omega .
$$

Evaluating (A.3) at $\hat{\omega}$ and substituting for $x_{\ell}^{i}(\hat{\omega}) p_{\ell}(\hat{\omega})^{\sigma}$, Eq. (A.5) can be solved for

$$
e^{i}\left[1-\beta\left(\frac{e^{i}}{P_{n}}\right)^{-\varepsilon}\right]=X_{\ell}^{i}\left[\int_{\omega \in \Omega} p_{\ell}(\omega)^{1-\sigma} d \omega\right]^{\frac{1}{1-\sigma}},
$$

making $P_{\ell} \equiv\left[\int_{\omega \in \Omega} p_{\ell}(\omega)^{1-\sigma} d \omega\right]^{\frac{1}{1-\sigma}}$ a valid price index for the composite $X_{\ell}^{i}$, because total expenditures of household $i$ devoted to luxuries are given by $P_{\ell} X_{\ell}^{i}$. This completes the proof.

\section{A.3 Rent sharing and social welfare}

Starting point is the welfare function in Eq. (21). Accounting for $\left(\frac{\bar{e}}{P_{n}}\right)^{\varepsilon} \hat{\psi}=\Lambda^{\varepsilon}\left[1+h_{\ell}\left(\alpha^{\varepsilon}-1\right)\right] \hat{\psi}_{\lambda}$, substituting the share of production workers $h_{\ell}$ from Eq. (19), the price index of luxuries from Eq. (20), and acknowledging $\kappa=\frac{\sigma}{\sigma+\alpha(\sigma-1)}$ as well as $\frac{\kappa}{1-B}=F(\alpha)^{-1}$, with $F(\alpha) \equiv 1+\frac{\sigma-1}{\sigma}\left[1+\left(\alpha^{1-\varepsilon}-1\right) \beta \Lambda^{-\varepsilon} \psi_{\lambda}\right]$, we can express welfare in the closed economy as a function of wage premium $\alpha: V\left(P_{n}, P_{\ell}, \bar{e}, \hat{\psi}\right)=$ 


$$
\begin{aligned}
& \left(\frac{H \Lambda\left(1-\beta \Lambda^{-\varepsilon} \psi_{\lambda}\right)}{\sigma f}\right)^{\frac{\varepsilon}{\sigma-1}} \hat{V}(\alpha), \text { with } \\
& \qquad \hat{V}(\alpha) \equiv \frac{1}{\varepsilon}\left(\alpha+\frac{\sigma}{\sigma-1}\right)^{-\varepsilon} F(\alpha)^{-\frac{\varepsilon}{\sigma-1}}\left\{\Lambda^{\varepsilon} \hat{\psi}_{\lambda}\left[1+\frac{\sigma-1}{\sigma}\left(1-\beta \Lambda^{-\varepsilon} \psi_{\lambda}\right) \frac{\alpha^{\varepsilon}-1}{F(\alpha)}\right]-\beta\right\}
\end{aligned}
$$

Differentiation with respect to $\alpha$ gives

$$
\begin{aligned}
\hat{V}^{\prime}(\alpha)=\frac{\varepsilon \hat{V}(\alpha)}{\alpha+\frac{\sigma}{\sigma-1}}\left\{-1-\frac{1-\varepsilon}{\sigma} \frac{\left(\alpha+\frac{\sigma}{\sigma-1}\right) \alpha^{-\varepsilon} \beta \Lambda^{-\varepsilon} \psi_{\lambda}}{F(\alpha)}\right. & \\
& \left.\quad+\frac{\left(\alpha+\frac{\sigma}{\sigma-1}\right) \Lambda^{\varepsilon} \hat{\psi}_{\lambda} \frac{\sigma-1}{\sigma}\left(1-\beta \Lambda^{-\varepsilon} \psi_{\lambda}\right)}{\Lambda^{\varepsilon} \hat{\psi}_{\lambda}\left[1+\frac{\sigma-1}{\sigma}\left(1-\beta \Lambda^{-\varepsilon} \psi_{\lambda}\right) \frac{\alpha^{\varepsilon}-1}{F(\alpha)}\right]-\beta}\left[\frac{\alpha^{\varepsilon-1}}{F(\alpha)}-\frac{1-\varepsilon}{\varepsilon} \frac{\alpha^{\varepsilon}-1}{F(\alpha)} \frac{\frac{\sigma-1}{\sigma} \alpha^{-\varepsilon} \beta \Lambda^{-\varepsilon} \psi_{\lambda}}{F(\alpha)}\right]\right\} .
\end{aligned}
$$

Accounting for $\lim _{\varepsilon \rightarrow 0} F(\alpha)=\frac{2 \sigma-1}{\sigma}+\frac{\sigma-1}{\sigma}(\alpha-1) \beta, \lim _{\varepsilon \rightarrow 0} \frac{1-\varepsilon}{\varepsilon}\left(\alpha^{\varepsilon}-1\right)=\ln \alpha$, and $\lim _{\varepsilon \rightarrow 0} \varepsilon \hat{V}(\alpha)=$ $1-\beta$, we compute

$$
\begin{array}{r}
\lim _{\varepsilon \rightarrow 0} \hat{V}^{\prime}(\alpha)=\frac{1-\beta}{\alpha+\frac{\sigma}{\sigma-1}}\left\{-1-\frac{\beta}{\sigma} \frac{\alpha+\frac{\sigma}{\sigma-1}}{\frac{2 \sigma-1}{\sigma}+\frac{\sigma-1}{\sigma}(\alpha-1) \beta}+\frac{\frac{\sigma-1}{\sigma}+\frac{1}{\alpha}}{\frac{2 \sigma-1}{\sigma}+\frac{\sigma-1}{\sigma}(\alpha-1) \beta}\right. \\
\left.-\frac{\sigma-1}{\sigma} \frac{\beta \ln \alpha\left(\frac{\sigma-1}{\sigma} \alpha+1\right)}{\left[\frac{2 \sigma-1}{\sigma}+\frac{\sigma-1}{\sigma}(\alpha-1) \beta\right]^{2}}\right\},
\end{array}
$$

where $\frac{\sigma-1}{\sigma}+\frac{1}{\alpha}<\frac{2 \sigma-1}{\sigma}+\frac{\sigma-1}{\sigma}(\alpha-1) \beta$ proves that $\lim _{\varepsilon \rightarrow 0} \hat{V}^{\prime}(\alpha)<0$. This confirms that a higher wage premium in the sector producing luxuries lowers welfare in the Cobb-Douglas case. Furthermore, accounting for $\lim _{\varepsilon \rightarrow 1} F(\alpha)=\frac{2 \sigma-1}{\sigma}$, we can compute $\lim _{\varepsilon \rightarrow 1} \hat{V}(\alpha)=(\Lambda-\beta) \frac{\sigma-1}{\sigma}\left(\frac{\sigma}{2 \sigma-1}\right)^{\frac{\sigma}{\sigma-1}}$ and thus $\lim _{\varepsilon \rightarrow 1} \hat{V}^{\prime}(\alpha)=0$. Finally, setting $\alpha=1$ establishes

$$
\hat{V}^{\prime}(1)=\frac{\varepsilon \hat{V}(1)(\sigma-1) \beta}{2 \sigma-1}\left[\frac{1-\beta \Lambda^{-\varepsilon} \psi_{\lambda}}{\Lambda^{\varepsilon} \hat{\psi}_{\lambda}-\beta}-\frac{\sigma-\varepsilon}{\sigma-1} \Lambda^{-\varepsilon} \psi_{\lambda}\right],
$$

which can be positive for sufficiently high levels of $\sigma$ and negative for sufficiently low ones. This completes the proof.

\section{A.4 Derivation and discussion of constraints (31) and (32)}

From Eq. (29), the constraint for a positive production level of necessities at home, $h_{\ell}<1$, can be rewritten as

$$
\kappa \frac{\sigma-1}{\sigma}\left[1-\beta \Lambda^{-\varepsilon} \psi_{\lambda}\right]<\frac{\mu+t}{1+t}-B .
$$

Acknowledging Eq. (28), we can compute

$$
\frac{\mu+t}{1+t}=1+\frac{\rho(1-B)-\left(1-B^{*}\right)}{\left[t-B^{*}(1+t)\right]-\rho}=1+\frac{\rho(1-B)-\left(1-B^{*}\right)}{\bar{\rho}(t)-\rho},
$$


where the second equality sign follows from the definition of $\bar{\rho}(t)$. Substituting Eq. (A.10) into (A.9) then gives

$$
\kappa \frac{\sigma-1}{\sigma}\left[1-\beta \Lambda^{-\varepsilon} \psi_{\lambda}\right]<1-B+\frac{\rho(1-B)-\left(1-B^{*}\right)}{\bar{\rho}(t)-\rho} \equiv \hat{g}_{0}(t),
$$

which is fulfilled if $\rho \geq 1$. To see this, note that with $H \Lambda=H^{*} \Lambda^{*}, \rho>1 \mathrm{implies} \rho(1-B)>1-B^{*}$, so that $\hat{g}_{0}(t)>1-B$. Noting that $1-B>\kappa \frac{\sigma-1}{\sigma}\left[1-\beta \Lambda^{-\varepsilon} \psi_{\lambda}\right]$, this is sufficient for a positive production level of necessities at home. In contrast, $\rho<1$ and thus $\rho(1-B)<1-B^{*}$ imply $\hat{g}_{0}(t)<1-B$. However, since $\hat{g}_{0}^{\prime}(t)>0$ and $\lim _{t \rightarrow \infty} \hat{g}_{0}(t)=1-B$ hold in this case, we can safely conclude that the condition in (A.11) is fulfilled for sufficiently high $t$.

In a next step, we combine Eq. (30) with the constraint for a positive production level of necessities abroad, $h_{\ell}^{*}<1$, and obtain

$$
\kappa \frac{\sigma-1}{\sigma}\left[1-\beta\left(\Lambda^{*}\right)^{-\varepsilon} \psi_{\lambda}^{*}\right]<\frac{1+\mu t}{\mu(1+t)}-B^{*} .
$$

Acknowledging Eq. (28), we can compute

$$
\frac{1+\mu t}{\mu(1+t)}=1+\frac{\left.\left(1-B^{*}\right)-\rho(1-B)\right]}{\rho[t-B(1+t)]-1}=1+\frac{\left[\left(1-B^{*}\right)-\rho(1-B)\right]}{\rho / \underline{\rho}(t)-1},
$$

where the second equality sign follows from the definition of $\underline{\rho}(t)$. Substituting Eq. (A.13) into (A.12), we get

$$
\kappa \frac{\sigma-1}{\sigma}\left[1-\beta\left(\Lambda^{*}\right)^{-\varepsilon} \psi_{\lambda}^{*}\right]<1-B^{*}+\frac{\left(1-B^{*}\right)-\rho(1-B)}{\rho / \underline{\rho}(\tau)-1} \equiv \hat{g}_{1}(t) .
$$

For $\rho \leq 1$ and thus $1-B^{*} \geq \rho(1-B)$, we have $\hat{g}_{1}(t) \geq 1-B^{*}$, which noting that $1-B^{*}>$ $\kappa \frac{\sigma-1}{\sigma}\left[1-\beta\left(\Lambda^{*}\right)^{-\varepsilon} \psi_{\lambda}^{*}\right]$ is sufficient for (A.14). In contrast, we have $\hat{g}_{1}(t)<1-B^{*}$ if $\rho>1$ and thus $1-B^{*}<\rho(1-B)$, and in this case it is a priori not clear that (A.14) holds. However, acknowledging that $\rho>1$ gives $\hat{g}_{1}^{\prime}(t)>0$ while $\lim _{t \rightarrow \infty} \hat{g}_{1}(t)=1-B^{*}$ holds for any $\rho$, it follows that (A.14) must be fulfilled for a sufficiently high level of $t$. This completes the proof.

\section{A.5 Relative market size differences and overall trade}

Consider first $\rho<1$, which implies that home is a net-exporter of luxuries, according to Proposition 1. As shown in the main text, total exports plus imports of home are then given by $2 E X_{\ell}$, which equals exports plus imports of the foreign economy due to balanced trade. Accounting for $E X_{\ell}=M r /(1+t)$, Eqs. (17) and (29) establish

$$
E X_{\ell}=\frac{H \Lambda w\left[1-\beta \Lambda^{-\varepsilon} \psi_{\lambda}\right]}{(\mu+t)-B(1+t)}=H \Lambda w\left[1-\beta \Lambda^{-\varepsilon} \psi_{\lambda}\right] \frac{\rho(t)[\bar{\rho}(t)-\rho]}{\bar{\rho}(t)-\underline{\rho}(t)},
$$

where the second equality sign follows from substituting Eq. (28) for $\mu$ and acknowledging the definitions of $\underline{\rho}(t), \bar{\rho}(t)$. In a similar vein, we can note that $\rho>1$ makes home a net-importer of luxuries, with total 
exports and imports given by $2 I M_{\ell}$. Accounting for $I M_{\ell}=M \mu r /(1+t)$, Eqs. (17) and (29) establish

$$
I M_{\ell}=\frac{H \Lambda w\left[1-\beta \Lambda^{-\varepsilon} \psi_{\lambda}\right] \mu}{(\mu+t)-B(1+t)}=H \Lambda w\left[1-\beta \Lambda^{-\varepsilon} \psi_{\lambda}\right] \frac{\rho-\underline{\rho}(t)}{\bar{\rho}(t)-\underline{\rho}(t)},
$$

where the second equality sign follows from substituting Eq. (28) for $\mu$ and acknowledging the definitions of $\underline{\rho}(t), \bar{\rho}(t)$. Noting that $d E X_{\ell} / d \rho<0$ while $d I M_{\ell} / d \rho>0$ completes the proof.

\section{A.6 Properties of price index (37) and proof of Proposition 2}

Substituting Eq. (28) for $\mu$ into Eq. (37), gives $P_{\ell}=P_{\ell}^{a} F(t)^{\frac{1}{1-\sigma}}$, with

$$
F(t) \equiv \frac{1+t}{t} \frac{1-B}{1-B \frac{1+t}{\mu+t}}=(1-B) \frac{1+t}{t} \frac{\bar{\rho}(t)-\rho B-\left(1-B^{*}\right)}{\bar{\rho}(t)(1-B)-\left(1-B^{*}\right)} .
$$

Differentiation with respect to $t$ gives $F^{\prime}(t)=-\hat{F}(t)(1-B) / t^{2}$, with

$$
\hat{F}(t) \equiv 1+B \frac{\bar{\rho}(t)-\rho}{\bar{\rho}(t)(1-B)-\left(1-B^{*}\right)}-B\left(1-B^{*}\right) t(1+t) \frac{\rho(1-B)-\left(1-B^{*}\right)}{\left[\bar{\rho}(t)(1-B)-\left(1-B^{*}\right)\right]^{2}}
$$

and $\bar{\rho}(t)(1-B)>1-B^{*}$ from the parameter constraint in (31). Then, noting that $\rho>,=,<1$ establishes $\rho(1-B)>,=,<1-B^{*}$ it is immediate that $\hat{F}(t)>0$ and thus $F^{\prime}(t)<0$ if $\rho \leq 1$. Furthermore, accounting for $\lim _{t \rightarrow \infty} \hat{F}(t)=[1 /(1-B)]^{2}\left[1-\rho B(1-B) /\left(1-B^{*}\right)\right]$, we can safely conclude that $\lim _{t \rightarrow \infty} \hat{F}(t)=0$ defines a unique $\hat{\rho}=\left(1-B^{*}\right) / B(1-B)>1$, such that $\lim _{t \rightarrow \infty} \hat{F}(t)>(<) 0$ if $\rho<(>) \hat{\rho}$. Then, provided that $\rho>\hat{\rho}, F^{\prime}(t)>0$ holds for sufficiently high $t$. Noting finally that $\lim _{t \rightarrow \infty} F(t)=1$, we can safely conclude that $F(t)>1$ and thus $P_{\ell}<P_{\ell}^{a}$ if $\rho \leq 1$, whereas $F(t)<1$ and thus $P_{\ell}>P_{\ell}^{a}$ is guaranteed for high levels of $t$ if $\rho>\hat{\rho}$. This completes the proof.

\section{A.7 Formal details for the analysis in Section 4.1}

We begin with a brief discussion of the second-order conditions for the profit-maximization problem of firms producing luxuries. The second-order conditions for an interior maximum require that evaluated at the optimum the Hessian matrix

$$
\mathbf{H}=\left(\begin{array}{cc}
\frac{\partial^{2} \Pi}{\partial q_{\ell}^{2}} & \frac{\partial^{2} \Pi}{\partial q_{\ell} \partial \lambda_{u}} \\
\frac{\partial^{2} \Pi}{\partial \lambda_{u} \partial q_{\ell}} & \frac{\partial^{2} \Pi}{\partial \lambda_{u}^{2}}
\end{array}\right)
$$

is negative semidefinite, implying that for any column vector $\mathbf{h} \equiv\left(h_{1}, h_{2}\right) \neq 0, \mathbf{h}^{t} \mathbf{H h} \leq 0$. From Eq. $\left(13^{\prime}\right)$, we have

$$
\frac{\partial^{2} \Pi}{\partial q_{\ell}^{2}}=-\frac{\sigma-1}{\sigma} \frac{1}{\sigma} \frac{\kappa r}{q_{\ell}^{2}}, \quad \frac{\partial^{2} \Pi}{\partial q_{\ell} \partial \lambda_{u}}=\frac{\partial^{2} \Pi}{\partial \lambda_{u} \partial q_{\ell}}=\frac{P_{n}}{\Lambda_{u}} \frac{1}{\lambda_{u}}, \quad \frac{\partial^{2} \Pi}{\partial \lambda_{u}^{2}}=-2 \frac{P_{n}}{\Lambda_{u}} \frac{q_{\ell}}{\lambda_{u}^{2}}-P_{n} \varphi(\varphi-1) \frac{F\left(\lambda_{u}\right)}{\lambda_{u}^{2}} .
$$


Evaluating these second derivatives at the first-order conditions $\partial \Pi / \partial q_{\ell}=0, \partial \Pi / \partial \lambda_{u}=0$, we can compute

$$
\mathbf{h}^{t} \mathbf{H h}=-\frac{P_{n}}{\Lambda_{u}} \frac{1}{\sigma q_{\ell}}\left[h_{1}^{2}-2 h_{1} h_{2} \frac{\sigma q_{\ell}}{\lambda_{u}}+h_{2}^{2} \sigma(1+\varphi)\left(\frac{q_{\ell}}{\lambda_{u}}\right)^{2}\right] .
$$

Accounting for $\varphi>\sigma-1$, we obtain

$$
\mathbf{h}^{t} \mathbf{H h} \leq-\frac{P_{n}}{\Lambda_{u}} \frac{1}{\sigma q_{\ell}}\left[h_{1}^{2}-2 h_{1} h_{2} \frac{\sigma q_{\ell}}{\lambda_{u}}+h_{2}^{2}\left(\frac{\sigma q_{\ell}}{\lambda_{u}}\right)^{2}\right]=-\frac{P_{n}}{\Lambda_{u}} \frac{1}{\sigma q_{\ell}}\left(h_{1}-h_{2} \frac{\sigma q_{\ell}}{\lambda_{u}}\right)^{2}
$$

which confirms that the Hessian matrix is negative semidefinite.

In a next step, we derive Eqs. $\left(17^{\prime}\right)$ and $\left(18^{\prime}\right)$. For this purpose, we first acknowledge that denoting by $h_{\ell}$ the share of workers finding employment in the sector of luxuries and denoting by $\gamma_{h}=h_{\ell}\left(\hat{\lambda}_{u} / \underline{\lambda}\right)^{g}$ the share of workers with effective labor supply $\lambda>\hat{\lambda}_{u}$, we can write total employment of workers in the sector of luxuries as $M q_{\ell}=H \gamma_{h} \int_{\hat{\lambda}_{u}}^{\bar{\lambda}} \lambda d L(\lambda)=H h_{\ell} \hat{\Lambda}_{u}$, where the second equality sign makes use of the Pareto assumption and $\hat{\Lambda}_{u}=\frac{g}{g-1} \hat{\lambda}_{u}$. From Eq. (13'), we then obtain $\frac{\sigma-1}{\sigma} \Lambda_{u} \kappa M r=H h_{\ell} \hat{\Lambda}_{u} w$, where $w=P_{n}$ has been used. Accounting for $\alpha=\eta^{-1}, \hat{\alpha}=\alpha \hat{\Lambda}_{u}^{-1}$, finally establishes Eq. $\left(17^{\prime}\right)$.

In a final step, we derive Eq. $\left(18^{\prime}\right)$. For this purpose, we first compute

$$
\int_{i \in \mathcal{H}} e^{i} d i=H w \int_{\underline{\lambda}}^{\bar{\lambda}} \lambda d L(\lambda)+H w \gamma_{h}(\hat{\alpha}-1) \int_{\hat{\lambda}_{u}}^{\bar{\lambda}} \lambda d L(\lambda) .
$$

Making use of the Pareto assumption, we get $\int_{\underline{\lambda}}^{\bar{\lambda}} \lambda d L(\lambda)=\frac{g}{g-1} \underline{\lambda}=\Lambda$ and $\int_{\hat{\lambda}_{u}}^{\bar{\lambda}} \lambda d L(\lambda)=\left(\frac{\hat{\lambda}_{u}}{\underline{\underline{\lambda}}}\right)^{-g} \frac{g}{g-1} \hat{\lambda}_{u}=$ $\left(\frac{\hat{\lambda}_{u}}{\underline{\underline{\lambda}}}\right)^{-g} \hat{\Lambda}_{u}$. Accounting for $\gamma_{h}=h_{\ell}\left(\frac{\hat{\lambda}_{u}}{\underline{\underline{\lambda}}}\right)^{g}$, we then obtain

$$
\int_{i \in \mathcal{H}} e^{i} d i=H w \Lambda+H w h_{\ell}(\hat{\alpha}-1) \hat{\Lambda}_{u}
$$

We further compute

$$
\int_{i \in \mathcal{H}} e^{i}\left(\frac{e^{i}}{P_{n}}\right)^{-\varepsilon} d i=H w \int_{\underline{\lambda}}^{\bar{\lambda}} \lambda^{1-\varepsilon} d L(\lambda)+H w \gamma_{h}\left(\hat{\alpha}^{1-\varepsilon}-1\right) \int_{\hat{\lambda}_{u}}^{\bar{\lambda}} \lambda^{1-\varepsilon} d L(\lambda),
$$

where $w=P_{n}$ has been used. Applying the Pareto assumption, we can determine $\int_{\underline{\lambda}}^{\bar{\lambda}} \lambda^{1-\varepsilon} d L(\lambda)=$ $\frac{g}{g+\varepsilon-1} \underline{\lambda}^{1-\varepsilon}=\Lambda^{1-\varepsilon} \psi_{\lambda}$, with $\psi_{\lambda}$ defined in the main text, and $\int_{\hat{\lambda}_{u}}^{\bar{\lambda}} \lambda^{1-\varepsilon} d L(\lambda)=\left(\frac{\hat{\lambda}_{u}}{\underline{\lambda}}\right)^{-g} \hat{\Lambda}_{u}^{1-\varepsilon} \psi_{\lambda}$. Substitution into Eq. (A.24), then gives

$$
\int_{i \in \mathcal{H}} e^{i}\left(\frac{e^{i}}{P_{n}}\right)^{-\varepsilon} d i=H w \Lambda^{1-\varepsilon} \psi_{\lambda}+H w h_{\ell}\left(\hat{\alpha}^{1-\varepsilon}-1\right) \hat{\Lambda}_{u}^{1-\varepsilon} \psi_{\lambda}
$$

Substituting Eqs. (A.23) and (A.25) into $M r=\int_{i \in \mathcal{H}} e^{i}\left[1-\beta\left(\frac{e^{i}}{P_{n}}\right)^{-\varepsilon}\right] d i$, we obtain Eq. (18'). This completes the proof. 


\section{A.8 Formal details for the analysis in Section 4.2}

We first show the derivation details for Eq. $\left(23^{\prime}\right)$. For this purpose, we introduce the auxiliary variables $E_{\ell} \equiv H \Lambda w\left[1-\beta \Lambda^{-\varepsilon} \psi_{\lambda}\right]$ and $E_{\ell}^{*} \equiv H \Lambda w\left[1-\beta \Lambda^{-\varepsilon} \psi_{\lambda}\right]+h_{\ell}^{*} H \Lambda w \frac{\sigma}{\sigma-1} \frac{1}{\kappa^{*}} B^{*}$ to denote economy-wide expenditures for luxury goods at home and abroad. Then, we can determine total revenues of home and foreign firms producing luxuries according to

$$
r=E_{\ell}\left(\frac{p_{\ell}}{P_{\ell}}\right)^{1-\sigma}+\frac{E_{\ell}^{*}}{t}\left(\frac{p_{\ell}}{P_{\ell}^{*}}\right)^{1-\sigma}, \quad r^{*}=E_{\ell}^{*}\left(\frac{p_{\ell}^{*}}{P_{\ell}^{*}}\right)^{1-\sigma}+\frac{E_{\ell}}{t}\left(\frac{p_{\ell}^{*}}{P_{\ell}}\right)^{1-\sigma},
$$

where $\kappa=\frac{\sigma}{2 \sigma-1}>\frac{\sigma}{\sigma+(\sigma-1) \alpha^{*}}=\kappa^{*}$ and thus $p_{\ell}=\frac{\sigma}{\sigma-1} \frac{w}{\kappa}<\frac{\sigma}{\sigma-1} \frac{w}{\kappa^{*}}=p_{\ell}^{*}$. Using the zero-profit conditions $\kappa r=\sigma P_{n} f, \kappa^{*} r^{*}=\sigma P_{n} f$ and accounting for $\xi=\frac{p_{\ell}^{*}}{p_{\ell}}=\frac{\kappa}{\kappa^{*}}$, we derive

$$
\frac{E_{\ell}^{*}}{\left(P_{\ell}^{*}\right)^{1-\sigma}}=\frac{t \xi^{\sigma}-1}{t-\xi^{\sigma}} \frac{E_{\ell}}{P_{\ell}^{1-\sigma}}
$$

which, substituting for $E_{\ell}$ and $E_{\ell}^{*}$, can be reformulated to Eq. $\left(23^{\prime}\right)$.

To determine the sign of $d \mu / d t$ in Eq. $\left(33^{\prime}\right)$, we can make use of three insights. First, from Eq. $\left(28^{\prime}\right)$ it follows that $\mu>0$ holds if and only if $t>\xi^{\sigma}+\sqrt{\xi^{2 \sigma}-1} \equiv \underline{t}$. Second, we can show that $t\left(1-B^{*}\right)-\xi^{-\sigma}>0$. To see this, note that $t>\underline{t}$ establishes $t>\xi^{\sigma}$ and thus $t\left(1-B^{*}\right)-\xi^{-\sigma}>\xi^{\sigma}(1-$ $\left.B^{*}\right)-\xi^{-\sigma} \equiv g\left(\alpha^{*}\right)$. Since both $\xi=\frac{\sigma+(\sigma-1) \alpha^{*}}{2 \sigma-1}$ and $\xi\left(1-B^{*}\right)=1+\frac{\sigma-1}{2 \sigma-1}\left[\left(\alpha^{*}\right)^{1-\varepsilon}-1\right] \beta \Lambda^{-\varepsilon} \psi_{\lambda}$ increase in $\alpha^{*}$, we have $g^{\prime}\left(\alpha^{*}\right)>0$, so that $g(1)=0$ gives $g\left(\alpha^{*}\right)>0$ and thus $t\left(1-B^{*}\right)-\xi^{-\sigma}>0$ for all $\alpha^{*}>1$. Third, defining $G(t) \equiv \frac{t-\xi^{\sigma}}{t\left(1-B^{*}\right)-\xi^{-\sigma}}$, we can compute $G^{\prime}(t)>,=,<0$ if $\xi^{\sigma}\left(1-B^{*}\right)-\xi^{-\sigma}>,=,<0$. Hence, $G^{\prime}(t)>0$ follows from $g\left(\alpha^{*}\right)>0$. This establishes $\left.\frac{d^{2} \mu}{d t^{2}}\right|_{\frac{d \mu}{d t}=0}>0$, according to Eq. (33'). We can thus conclude that if $\mu$ had an extremum in $t$, it would be a minimum. Evaluated at $t=\underline{t}$, we have $\frac{1}{\xi} \frac{t-\xi^{\sigma}}{t\left(1-B^{*}\right)-\xi^{-\sigma}}-\mu=\frac{1}{\xi} \frac{\underline{t}-\xi^{\sigma}}{\underline{t}\left(1-B^{*}\right)-\xi^{-\sigma}}>0$, implying $d \mu / d t>0$ for small values of $t$ higher than $\underline{t}$. This is inconsistent with a minimum of $\mu$ and proves that $d \mu / d t>0$ for all possible $t .{ }^{17}$

In a final step, we determine the welfare effects of trade and begin with the analysis of home. Substituting zero-profit condition $\kappa r=\sigma P_{n} f$ into Eq. $\left(26^{\prime}\right)$ and accounting for $\frac{r^{*}}{r}=\frac{\kappa}{\kappa^{*}}=\xi$, we can compute

$$
\kappa \frac{\sigma-1}{\sigma} \frac{H \Lambda\left(1-\beta \Lambda^{-\varepsilon} \psi_{\lambda}\right)}{(\sigma-1) f} \frac{t-1}{t-\xi^{\sigma}}=\frac{t+\mu \xi^{1-\sigma}}{1+t} M
$$

Differentiating the left-hand side with respect to $t$, we find that $\frac{t+\mu \xi^{1-\sigma}}{1+t} M$ decreases in trade costs. Since $(1+t) / t$ also decreases in $t$, it follows from $P_{\ell}=p_{\ell}\left[M \frac{t+\mu \xi^{1-\sigma}}{1+t} \frac{1+t}{t}\right]^{\frac{1}{1-\sigma}}$ that home benefits from trade. ${ }^{18}$ To determine the welfare effects of trade for foreign, we first determine two auxiliary results. Starting

\footnotetext{
${ }^{17}$ To determine the effects of supply-side asymmetry on the Grubel-Lloyd index, we also need to know the sign of $d \mu / d \alpha^{*}$. Rearranging terms in Eq. $\left(28^{\prime}\right)$, we can rewrite the ratio of foreign to domestic firms as $\mu=\frac{t^{2}-2 t \xi^{\sigma}+1}{\left(t^{2}-1\right) \xi\left(1-B^{*}\right)-2 t \xi^{1-\sigma}+2 \xi}$. Noting $d \xi / d \alpha^{*}>0$ and $d \xi\left(1-B^{*}\right) / d \alpha^{*}>0$, we can safely conclude that $d \mu / d \alpha^{*}<0$. This is sufficient for $G L I=\mu \xi^{1-\sigma} \frac{t-\xi^{\sigma}}{t \xi^{\sigma}-1}$ to decrease in $\alpha^{*}$.

${ }^{18}$ Rearranging Eq. (A.27) we find that $M \frac{t-\xi^{\sigma}}{t^{2}-1}$ is inversely proportional to $\mu \xi^{1-\sigma}+t$ and therefore decreases in $t$. Noting from Eq. (34') that home's total exports of luxuries can be expressed as $E X_{\ell}=M \frac{t-\xi^{\sigma}}{t^{2}-1} \frac{t \xi^{\sigma}-1}{t-\xi^{\sigma}} \frac{\sigma P_{n} f}{\kappa}$, we can safely conclude that total (intra- plus inter-industry) trade decreases in $t$. Noting from Footnote 17 that $\mu \xi^{1-\sigma}$ decreases in $\alpha^{*}$, we can further conclude that $M \frac{t-\xi^{\sigma}}{t^{2}-1}$ increases in the foreign wage premium and this is sufficient for total (intra- plus inter-industry trade) to increase in supply-side dissimilarity.
} 
from the market clearing condition in Eq. $\left(26^{\prime}\right)$ and accounting for $\frac{r}{r^{*}}=\xi^{-1}$ and $\kappa^{*} r^{*}=\sigma P_{n} f$, we can compute

$$
H \Lambda w\left(1-\beta \Lambda^{-\varepsilon} \psi_{\lambda}\right)=\left(t \xi^{-\sigma}-1\right)\left[\frac{t^{2}}{t^{2}-1}\left(1+\frac{1}{t \mu \xi^{1-\sigma}}\right)-1\right] M^{*} \frac{\sigma P_{n} f}{\kappa^{*}}
$$

and thus

$$
M^{*}=\kappa^{*} \frac{\sigma-1}{\sigma} \frac{H \Lambda\left(1-\beta \Lambda^{-\varepsilon} \psi_{\lambda}\right)}{(\sigma-1) f} \frac{t-1}{t \xi^{-\sigma}-1} \frac{(t+1) \mu \xi^{1-\sigma}}{\mu \xi^{1-\sigma}+t} .
$$

Then, differentiating $G_{0}(t) \equiv \frac{t-1}{t \xi^{-\sigma}-1} \frac{(t+1) \mu \xi^{1-\sigma}}{\mu \xi^{1-\sigma}+t}$, we compute $G_{0}^{\prime}(t)=\frac{G_{0}(t)}{(t-1)\left(t+\mu \xi^{1-\sigma}\right)} g_{0}(t)$, with

$$
g_{0}(t) \equiv-\left(1-\xi^{-\sigma}\right) \frac{t+\mu \xi^{1-\sigma}}{t \xi^{-\sigma}-1}-\left(1-\mu \xi^{1-\sigma}\right) \frac{t-1}{t+1}+\frac{d \mu}{d t} \frac{t(t-1)}{\mu} .
$$

Due to $\lim _{t \rightarrow \infty} \frac{t+\mu \xi^{1-\sigma}}{t \xi^{-\sigma}-1}=\xi^{\sigma}, \lim _{t \rightarrow \infty} \frac{d \mu}{d t} \frac{t(t-1)}{\mu}=2 \frac{\left(1-B^{*}\right) \xi^{\sigma}-\xi^{-\sigma}}{1-B^{*}}$, and $\lim _{t \rightarrow \infty} \mu \xi^{1-\sigma}=\frac{\xi^{-\sigma}}{1-B^{*}}$, we can compute $\lim _{t \rightarrow \infty} g_{0}(t)=\frac{\left(1-B^{*}\right) \xi^{\sigma}-\xi^{-\sigma}}{1-B^{*}}$, which is zero if $\alpha^{*}=1$ and is positive if $\alpha^{*}>1$.

From Eq. (A.28) we furthermore obtain

$$
M^{*}\left[1+\frac{1}{t \mu \xi^{1-\sigma}}\right]=\kappa^{*} \frac{\sigma-1}{\sigma} \frac{H \Lambda\left(1-\beta \Lambda^{-\varepsilon} \psi_{\lambda}\right)}{(\sigma-1) f} \frac{t-1}{t \xi^{-\sigma}-1} \frac{t+1}{t} \frac{t \mu \xi^{1-\sigma}+1}{t+\mu \xi^{1-\sigma}} .
$$

Differentiating $G_{1}(t) \equiv \frac{t-1}{t \xi^{-\sigma}-1} \frac{t+1}{t} \frac{t \mu \xi^{1-\sigma}+1}{t+\mu \xi^{1-\sigma}}$ gives $G_{1}^{\prime}(t)=\frac{G_{1}(t)}{(t-1)\left(t+\mu \xi^{1-\sigma}\right)} g_{1}(t)$, with

$$
\begin{aligned}
g_{1}(t) \equiv-\left(1-\xi^{-\sigma}\right) \frac{t+\mu \xi^{1-\sigma}}{t \xi^{-\sigma}-1}-\frac{\left(t+\mu \xi^{1-\sigma}\right)(t-1)}{t(t+1)} & \\
-\frac{t-1}{t \mu \xi^{1-\sigma}+1} & {\left[1-\left(\mu \xi^{1-\sigma}\right)^{2}-\frac{d \mu}{d t}\left(t^{2}-1\right) \xi^{1-\sigma}\right] . }
\end{aligned}
$$

Accounting for $\lim _{t \rightarrow \infty} \frac{t+\mu \xi^{1-\sigma}}{t \xi^{-\sigma}-1}=\xi^{\sigma}, \lim _{t \rightarrow \infty} \frac{t-1}{t \mu \xi^{1-\sigma}+1}=\xi^{\sigma}\left(1-B^{*}\right), \lim _{t \rightarrow \infty} \mu \xi^{1-\sigma}=\frac{\xi^{-\sigma}}{1-B^{*}}$, and $\lim _{t \rightarrow \infty} \frac{d \mu}{d t}\left(t^{2}-1\right) \xi^{1-\sigma}=2 \frac{\xi^{\sigma}\left(1-B^{*}\right)-\xi^{-\sigma}}{1-B^{*}} \frac{\xi^{-\sigma}}{1-B^{*}}$, we compute $\lim _{t \rightarrow \infty} g_{1}(t)=\frac{B^{*}\left(1-B^{*}\right) \xi^{\sigma}-\xi^{-\sigma}}{1-B^{*}} \equiv$ $\tilde{g}_{1}\left(\alpha^{*}\right)$. Accounting for $\tilde{g}_{1}(1)=-1, \lim _{\alpha^{*} \rightarrow \infty} \tilde{g}_{1}\left(\alpha^{*}\right)=\infty$, and $\tilde{g}_{1}^{\prime}\left(\alpha^{*}\right)>0$, we can safely conclude that there exists a critical $\underline{\alpha}^{*}>1$, such that $\lim _{t \rightarrow \infty} g_{1}(t)>,=,<0$ if $\alpha^{*}>,=,<\underline{\alpha}^{*}$. From $P_{\ell}^{*}=p_{\ell}^{*}\left[M^{*} \frac{1+t \mu \xi^{1-\sigma}}{t \mu \xi^{1-\sigma}}\right]^{\frac{1}{1-\sigma}}$, it then follows that for initially high trade costs, the foreign price index of luxuries decreases in $t$ if $\alpha^{*}$ and therefore $\xi$ are sufficiently high.

Differentiating the welfare function $V\left(P_{n}, P_{\ell}^{*}, \bar{e}^{*}, \hat{\psi}\right)$ from Eq. (21), we finally obtain

$$
\frac{d V(\cdot)}{d t}=\frac{V(\cdot)}{(t-1)\left(t+\mu \xi^{1-\sigma}\right)}\left[\frac{\varepsilon}{\sigma-1} g_{1}(t)+\frac{\Lambda^{\varepsilon} \hat{\psi}_{\lambda} h_{\ell}^{*}\left[\left(\alpha^{*}\right)^{\varepsilon}-1\right]}{\left.\Lambda^{\varepsilon} \hat{\psi}_{\lambda}\left\{1+h_{\ell}^{*}\left[\left(\alpha^{*}\right)^{\varepsilon}-1\right)\right]\right\}-\beta} g_{0}(t)\right],
$$

where $\left(\frac{\bar{e}^{*}}{P_{n}}\right)^{\varepsilon} \hat{\psi}=\Lambda^{\varepsilon} \hat{\psi}_{\lambda}\left\{1+h_{\ell}^{*}\left[\left(\alpha^{*}\right)^{\varepsilon}-1\right]\right\}$ and $h_{\ell}^{*}=M^{*} \frac{(\sigma-1) f}{H \Lambda}$ have been considered. Accounting for $\lim _{t \rightarrow \infty} g_{0}(t)>0$ and $\lim _{t \rightarrow \infty} g_{1}(t)=\frac{B^{*}\left(1-B^{*}\right) \xi^{\sigma}-\xi^{-\sigma}}{1-B^{*}}>0$ if $\alpha^{*}>\underline{\alpha}^{*}$, we can thus safely conclude that the foreign country loses from a small reduction of initially high trade costs if the price distortion in the labor market is sufficiently high. In the limiting case of $\alpha^{*}=1$, we have $\lim _{t \rightarrow \infty} g_{0}(t)=0$ and $\lim _{t \rightarrow \infty} g_{1}(t)=-1$, so that in this case the foreign country unambiguously benefits from a small 
reduction of initially high trade costs. This completes the proof. 